\title{
Supporting Information for Nicotine Refined: Crystal Engineering of (S)-Nicotinium Malate Salts
}

Devin J. Angevine ${ }^{\mathrm{a}}$, Kristine Joy Camacho ${ }^{\mathrm{a}}$, Javid Rzayev', and Jason B. Benedict ${ }^{\mathrm{a}}$ ${ }^{a}$ Department of Chemistry, University at Buffalo, Natural Sciences Complex, Buffalo, NY 14260-3000, USA

*jbb6@buffalo.edu 


\section{Supporting Information}

\section{Table of Contents}

Previously Reported Crystalline Solids Containing Nicotine ........................................................... 1

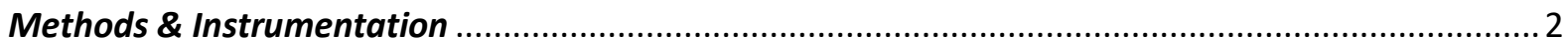

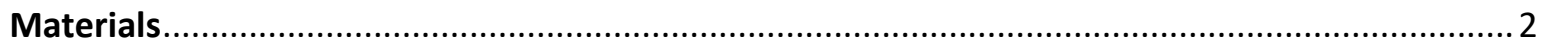

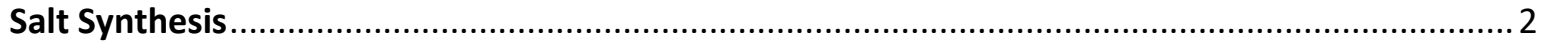

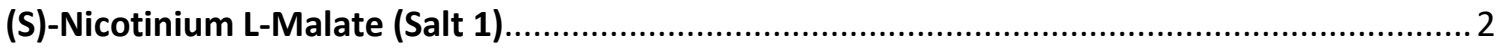

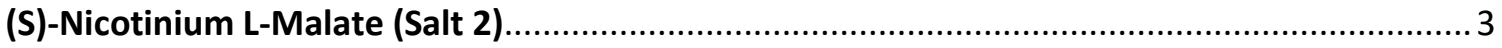

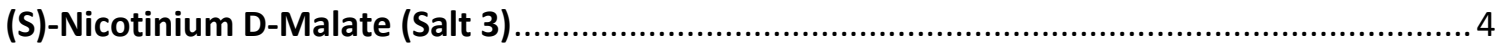

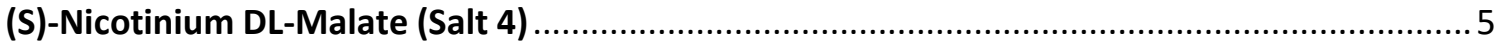

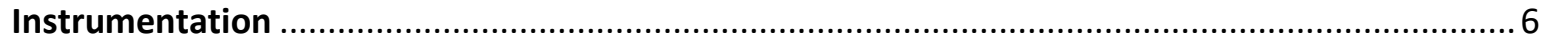

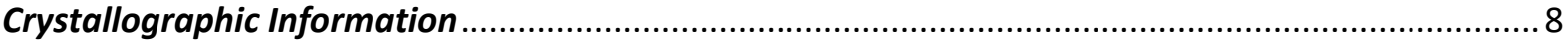

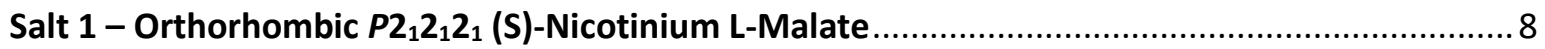

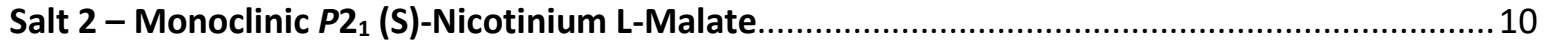

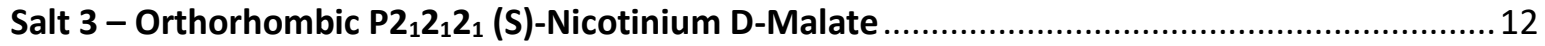

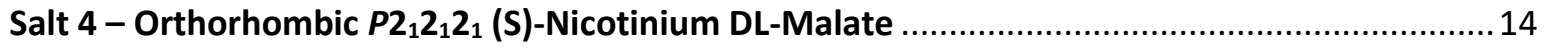

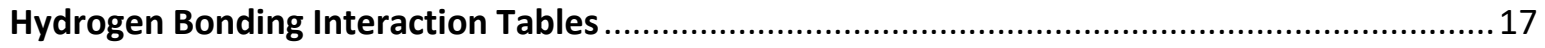

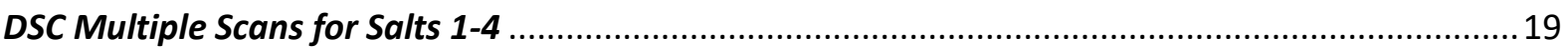

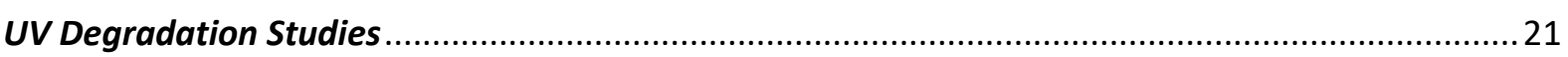

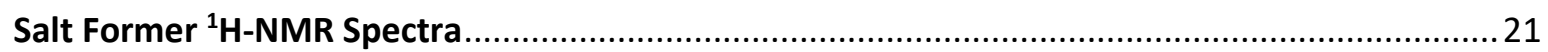

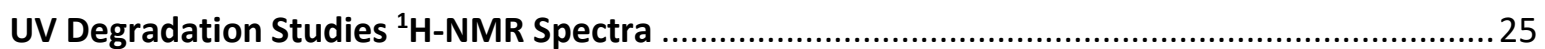




\section{Previously Reported Crystalline Solids Containing Nicotine}

Table S1: Melting points of previously reported nicotine-containing crystalline solids. The difference between the the coformer and co-crystal/salt melting points $\left(\Delta \mathrm{T}_{\mathrm{m}}\right)$ are calculated using NIST reference values for coformers.

\begin{tabular}{|c|c|c|c|c|c|}
\hline Refcode & $\begin{array}{l}\text { Form of } \\
\text { Nicotine }\end{array}$ & Coformer & $\begin{array}{l}\text { Non-Covalent } \\
\text { Interactions }\end{array}$ & $\begin{array}{l}\text { Crystal } \\
\text { Melting } \\
\text { Point } \\
\left({ }^{\circ} \mathbf{C}\right)\end{array}$ & $\begin{array}{l}\Delta \mathbf{T}_{\mathbf{m}} \\
\left({ }^{\circ} \mathbf{C}\right)\end{array}$ \\
\hline NICSAL & Protonated & Salicylic acid & $\begin{array}{l}\text { Hydrogen bonding / } \\
\text { ionic }\end{array}$ & 117.5 & 41.4 \\
\hline LAZXIW & Neutral & $\begin{array}{c}1,4- \\
\text { Bis(diphenylhydroxy } \\
\text { methyl)benzene }\end{array}$ & Hydrogen Bonding & 92.0 & 77.0 \\
\hline DOXSIS & Protonated & Iodine & $\begin{array}{l}\text { Hydrogen bonding / } \\
\text { ionic }\end{array}$ & 76.9 & 36.8 \\
\hline LAZXOC & Neutral & $\begin{array}{c}4,4^{\prime}- \\
\text { Diiodooctafluorobip } \\
\text { henyl }\end{array}$ & Halogen Bonding & 68.0 & 78.0 \\
\hline LAZXES & Neutral & $\begin{array}{c}\text { diiodotetrafluoroben } \\
\text { zene }\end{array}$ & Halogen Bonding & 54.0 & 55.0 \\
\hline REYKEM & Protonated & Picric Acid & $\begin{array}{l}\text { Hydrogen bonding / } \\
\text { ionic }\end{array}$ & $\begin{array}{c}\text { Not } \\
\text { reported }\end{array}$ & $\mathrm{N} / \mathrm{A}$ \\
\hline POSROG & Protonated & 5-sulfosalicylic acid & $\begin{array}{l}\text { Hydrogen bonding / } \\
\text { ionic }\end{array}$ & $\begin{array}{c}\text { Not } \\
\text { reported }\end{array}$ & $\mathrm{N} / \mathrm{A}$ \\
\hline POSRIA & Protonated & $\begin{array}{l}\text { 3,5-dinitrosalicylic } \\
\text { acid }\end{array}$ & $\begin{array}{l}\text { Hydrogen bonding / } \\
\text { ionic }\end{array}$ & $\begin{array}{c}\text { Not } \\
\text { reported }\end{array}$ & $\mathrm{N} / \mathrm{A}$ \\
\hline BUQJUT & Protonated & $\begin{array}{l}\text { trans-tetrachloro- } \\
\text { bis(dimethylsulfoxid } \\
\text { e)-iridium(iii) }\end{array}$ & $\begin{array}{l}\text { Hydrogen bonding / } \\
\text { ionic }\end{array}$ & $\begin{array}{c}\text { Not } \\
\text { reported }\end{array}$ & $\mathrm{N} / \mathrm{A}$ \\
\hline AHEZAQ & Neutral & Macrocycle & Hydrogen Bonding & $\begin{array}{c}\text { Not } \\
\text { reported }\end{array}$ & $\mathrm{N} / \mathrm{A}$ \\
\hline KERSAB & Neutral & $\begin{array}{l}\text { 1,1,6,6,-tetraphenyl- } \\
\text { 2,4-hexadiyne-1,6- } \\
\text { diol }\end{array}$ & Hydrogen Bonding & $\begin{array}{c}\text { Not } \\
\text { reported }\end{array}$ & $\mathrm{N} / \mathrm{A}$ \\
\hline ZURTAK & Neutral & Macrocycle & Hydrogen Bonding & $\begin{array}{c}\text { Not } \\
\text { reported }\end{array}$ & $\mathrm{N} / \mathrm{A}$ \\
\hline ZURTAK01 & Neutral & Macrocycle & Hydrogen Bonding & $\begin{array}{c}\text { Not } \\
\text { reported }\end{array}$ & $\mathrm{N} / \mathrm{A}$ \\
\hline
\end{tabular}




\section{Methods \& Instrumentation}

\section{Materials}

(S)-nicotine (98\%) and L-(-)-malic acid (99\%) were each purchased from Alfa Aesar. D-(+)-malic acid (98\%) and DL-malic acid (98\%) were purchased from Combi-Blocks. Methanol (HPLC grade 99.9\%) and n-heptane (99\%) were each purchased from Fisher Scientific. Dimethyl sulfoxide-D6 (D, 99.9\%) and Methanol-D4 (D, 99.8\%) were purchased from Cambridge Isotope Laboratories Inc.

\section{Salt Synthesis}

\section{(S)-Nicotinium L-Malate (Salt 1)}

L-(-)-malic acid $(134.1 \mathrm{mg}, 1.0 \mathrm{mmol})$ was placed into a $20 \mathrm{~mL}$ scintillation vial. Methanol (3.0 mL) was added with vigorous agitation. (S)-Nicotine $(0.24 \mathrm{~mL}, 1.5 \mathrm{mmol})$ was added via micropipette in the dark to avoid degradation. The resulting solution was vortexed for 30 seconds at 3,000 rpm on a VWR Mini Vortexer MV I. The solution was then stored in the dark uncapped to allow for crystal formation while the solvent slowly evaporated. Once the solvent was evaporated, the crystalline product was collected via vacuum filtration and washed with n-heptane ( $3 \times 5 \mathrm{~mL})(157.4 \mathrm{mg}, 53.12 \%)$. The yield was computed based upon the formula weight of (S)-Nicotinium L-Malate (F.W. 296.3 g/mol). M.P. $116.4^{\circ}$ C; ${ }^{1} \mathrm{H}-\mathrm{NMR}$ (DMSO, $400 \mathrm{MHz}) \delta 8.54(\mathrm{~d}, 1 \mathrm{H}), 8.49(\mathrm{dt}, 1 \mathrm{H}), 7.77(\mathrm{dq}, 1 \mathrm{H}), 7.38(\mathrm{dd}, 1 \mathrm{H}), 4.17(\mathrm{t}, 1 \mathrm{H}), 3.33(\mathrm{t}, 1 \mathrm{H})$, $3.25(\mathrm{tt}, 1 \mathrm{H}), 2.60(\mathrm{~d}, 1 \mathrm{H}), 2.56(\mathrm{~d}, 1 \mathrm{H}), 2.46-2.35(\mathrm{~m}, 2 \mathrm{H}), 2.27-2.19(\mathrm{~m}, 1 \mathrm{H}), 2.16(\mathrm{~d}, 3 \mathrm{H})$, $1.96-1.77(\mathrm{~m}, 2 \mathrm{H}), 1.76-1.64(\mathrm{~m}, 1 \mathrm{H})$. 


\section{(S)-Nicotinium L-Malate (Salt 2)}

L-(-)-malic acid $(134.8 \mathrm{mg}, 1.0 \mathrm{mmol})$ was added into a $20 \mathrm{~mL}$ scintillation vial. Methanol (1.0 mL) was added with vigorous agitation. (S)-Nicotine $(0.40 \mathrm{~mL}, 2.5 \mathrm{mmol})$ was added via micropipette in the dark to avoid degradation. The resulting solution was vortexed for 30 seconds at 3,000 rpm on a VWR Mini Vortexer MV I. The solution was then stored in the dark uncapped to allow for crystal formation while the solvent slowly evaporated. Once the solvent evaporated, the crystalline product was collected via vacuum filtration, washing with n-heptane $(3 \times 5 \mathrm{~mL})(229.0 \mathrm{mg}, 77.28 \%)$. The yield was computed based upon the formula weight of (S)-Nicotinium L-Malate (F.W. 296.3 g/mol). M.P $122.2{ }^{\circ}$ C. ${ }^{1}$ H-NMR (DMSO, $400 \mathrm{MHz}) \delta 8.54(\mathrm{~d}, 1 \mathrm{H}), 8.49(\mathrm{tt}, 1 \mathrm{H}), 7.77(\mathrm{dq}, 1 \mathrm{H}), 7.38(\mathrm{dd}, 1 \mathrm{H}), 4.17(\mathrm{t}, 1 \mathrm{H}), 3.31(\mathrm{t}, 1 \mathrm{H})$, $3.24(\mathrm{ddd}, 1 \mathrm{H}), 2.58(\mathrm{dd}, 1 \mathrm{H}), 2.47-2.35(\mathrm{~m}, 2 \mathrm{H}), 2.28-2.12(\mathrm{~m}, 3 \mathrm{H}), 1.96-1.76(\mathrm{~m}, 2 \mathrm{H})$, $1.76-1.62(\mathrm{~m}, 1 \mathrm{H})$ 


\section{(S)-Nicotinium D-Malate (Salt 3)}

D-(+)-malic acid (134.6 mg, $1.0 \mathrm{mmol})$ was added into a $20 \mathrm{~mL}$ scintillation vial. Methanol (3.0 mL) was added with vigorous agitation. (S)-Nicotine $(0.16 \mathrm{~mL}, 1.0 \mathrm{mmol})$ was added via micropipette in the dark to avoid degradation. The resulting solution was vortexed for 30 seconds at 3,000 rpm on a VWR Mini Vortexer MV I. The solution was then stored in the dark, uncapped to allow for crystal formation while the solvent slowly evaporated. Once the solvent evaporated, the crystalline product was collected via vacuum filtration, washing with n-heptane ( $3 \times 5 \mathrm{~mL})(184.3 \mathrm{mg}, 62.20 \%)$. The yield was computed based upon the formula weight of (S)-Nicotinium D-Malate (F.W. 296.3 g/mol). M.P. 93.4 ${ }^{\circ}$ C; ${ }^{1} \mathrm{H}-\mathrm{NMR}$ (DMSO, $400 \mathrm{MHz}) \delta 8.54(\mathrm{~d}, 1 \mathrm{H}), 8.49(\mathrm{dd}, 1 \mathrm{H}), 7.77(\mathrm{dt}, 1 \mathrm{H}), 7.38(\mathrm{dd}, 1 \mathrm{H}), 4.18(\mathrm{t}, 1 \mathrm{H}), 3.34(\mathrm{t}, 1 \mathrm{H})$, $3.25(\mathrm{ddd}, 1 \mathrm{H}), 2.58(\mathrm{dd}, 1 \mathrm{H}), 2.47-2.36(\mathrm{~m}, 2 \mathrm{H}), 2.27-2.20(\mathrm{~m}, 1 \mathrm{H}), 2.17(\mathrm{~d}, 3 \mathrm{H}), 1.97-$ $1.77(\mathrm{~m}, 2 \mathrm{H}), 1.76-1.63(\mathrm{~m}, 1 \mathrm{H})$. 


\section{(S)-Nicotinium DL-Malate (Salt 4)}

DL-malic acid (269.8 mg, $2.0 \mathrm{mmol}$ ) was added into a $20 \mathrm{~mL}$ scintillation vial. Methanol $(5.0 \mathrm{~mL})$ was added with vigorous agitation. (S)-Nicotine $(0.48 \mathrm{~mL}, 3.0 \mathrm{mmol})$ was added via micropipette in the dark to avoid degradation. The resulting solution was vortexed for 30 seconds at 3,000 rpm on a VWR Mini Vortexer MV I. The solution was then stored in the dark, uncapped to allow for crystal formation while the solvent slowly evaporated. Once the solvent evaporated, the crystalline product was collected via vacuum filtration, washing with n-heptane ( $3 \times 5 \mathrm{~mL})(336.3 \mathrm{mg}, 56.75 \%)$. The yield was computed based upon the formula weight of (S)-Nicotinium DL-Malate (F.W. $296.3 \mathrm{~g} / \mathrm{mol}$ ). M.P. $77.8^{\circ} \mathrm{C} ;{ }^{1} \mathrm{H}-\mathrm{NMR}$ (DMSO, $400 \mathrm{MHz}) \delta 8.56(\mathrm{q}, 1 \mathrm{H}), 8.50(\mathrm{dd}, 1 \mathrm{H}), 7.79(\mathrm{dq}, 1 \mathrm{H}), 7.39(\mathrm{dd}, 1 \mathrm{H}), 4.18(\mathrm{t}, 1 \mathrm{H}), 3.40(\mathrm{t}, 1 \mathrm{H})$, $3.28(\mathrm{ddd}, 1 \mathrm{H}), 2.59(\mathrm{dd}, 1 \mathrm{H}), 2.49-2.37(\mathrm{~m}, 1 \mathrm{H}), 2.29-2.22(\mathrm{~m}, 1 \mathrm{H}), 2.20(\mathrm{~d}, 3 \mathrm{H}), 1.88$ (dddt, 2H), 1.74 (tdd, 1H).

Note: The DSC sample for Salt $\mathbf{4}$ was further recrystallized from methanol multiple times prior to the DSC scans to ensure it was free of any possible nicotine on the surface, washing with excess heptane and methanol upon collection. 


\section{Instrumentation}

X-ray Diffraction (XRD): X-ray diffraction data was collected using a Bruker SMART APEX2 CCD diffractometer installed at a rotating anode source (MoK $\alpha$ radiation, $\lambda=0.71073$ Å) and equipped with an Oxford Cryosystems (Cryostream700) nitrogen gas-flow apparatus. Five sets of data (360 frames each) were collected by the rotation method with $0.5^{\circ}$ framewidth $(\omega$ scan $)$ with unique exposure times for each single crystalline sample. Samples were run at $90 \mathrm{~K}$. Using Olex2, the structures were solved with intrinsic phasing via the ShelXT structure solution program and refined with the ShelXL software suite using least squares minimization. ${ }^{[20]}$ Images of the structures were created using Olex2 and the CSD: Mercury Visualization and Analysis of Crystal Structures software suite. ${ }^{[21]}$ Absolute configuration was assigned based upon the stereochemistry of the API (S)-nicotine. As the compound is a weak anomalous scatterer, the absolute structure parameter has been removed from the CIF.

Stuart SMP10 Melting Point (MP) Apparatus: A Stuart SMP10 melting point apparatus was utilized to measure the melting point of each of the synthesized compounds. 4 replicates were run for each compound. The plateau temperature was set to $100^{\circ} \mathrm{C}$ for Salt $\mathbf{1}$ and Salt $\mathbf{2}$ and then ramped at $2{ }^{\circ} \mathrm{C} /$ minute. The plateau temperature was set to $70{ }^{\circ} \mathrm{C}$ for Salt 3 and Salt 4 and ramped at $2^{\circ} \mathrm{C} /$ minute.

Differential Scanning Calorimetry (DSC): A differential scanning calorimeter, model DSC Q200 (TA Instrument, USA) was used to measure the thermal transitions of the samples. About $10 \mathrm{mg}$ of each synthesized compound was placed into an aluminum pan and sealed. Each sample was scanned from $0{ }^{\circ} \mathrm{C}$ to above the melting point observed on the Stuart SMP10 at 20 ${ }^{\circ} \mathrm{C} / \mathrm{min}$ under nitrogen flow (20mL/min.) for 2 full cycles. Enthalpy of fusion was computed from the integrated area under the curve and the entropy of fusion computed by applying Gibbs' free energy in accordance with equilibrium between the solid and liquid state being achieved at the fusion point. Sample decomposition (exploding sealed pans and/or mass loss with vented 
pans) was observed using $5{ }^{\circ} \mathrm{C} / \mathrm{min}$ scan rates presumably due to the samples being exposed to the higher temperatures for a longer duration as the decomposition temperature of pure malic acid is $225^{\circ} \mathrm{C}$, as noted by the European Chemical Agency.

UV Photodegradation: NMR analysis was done on a sample of each salt former, (S)-nicotine, and each of the synthesized (S)-nicotinium salts. Each sample was then irradiated with ultraviolet (UV) light in a home built vented box with air flow for 24 hours using four Southern New England Ultraviolet Company RPR - 3000A UV bulbs $(\lambda=300 \mathrm{~nm})$. NMR analysis was then carried out on each sample to screen for any UV photodegradation of products.

Nuclear Magnetic Resonance (NMR): NMR analysis was run on a Varian Inova-400 broadband spectrometer (400 MHz), using the deuterated solvent appropriately labelled in each spectrum. Spectra were normalized to an intensity of 100.80 transients were run on each UV stress tested sample. 


\section{Crystallographic Information}

\section{Salt 1 - Orthorhombic P21212, (S)-Nicotinium L-Malate}

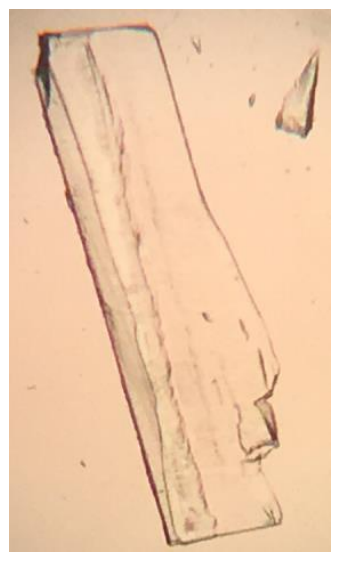

Figure S1: A crystal of orthorhombic $\quad P 2{ }_{1} 2_{1} 2_{1}$

(S)-nicotinium L-malate.

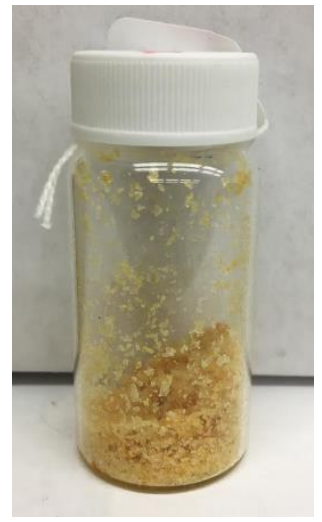

Figure S2: A vial of crystals of orthorhombic $P 22_{1} 2_{1}$ (S)-nicotinium Lmalate.

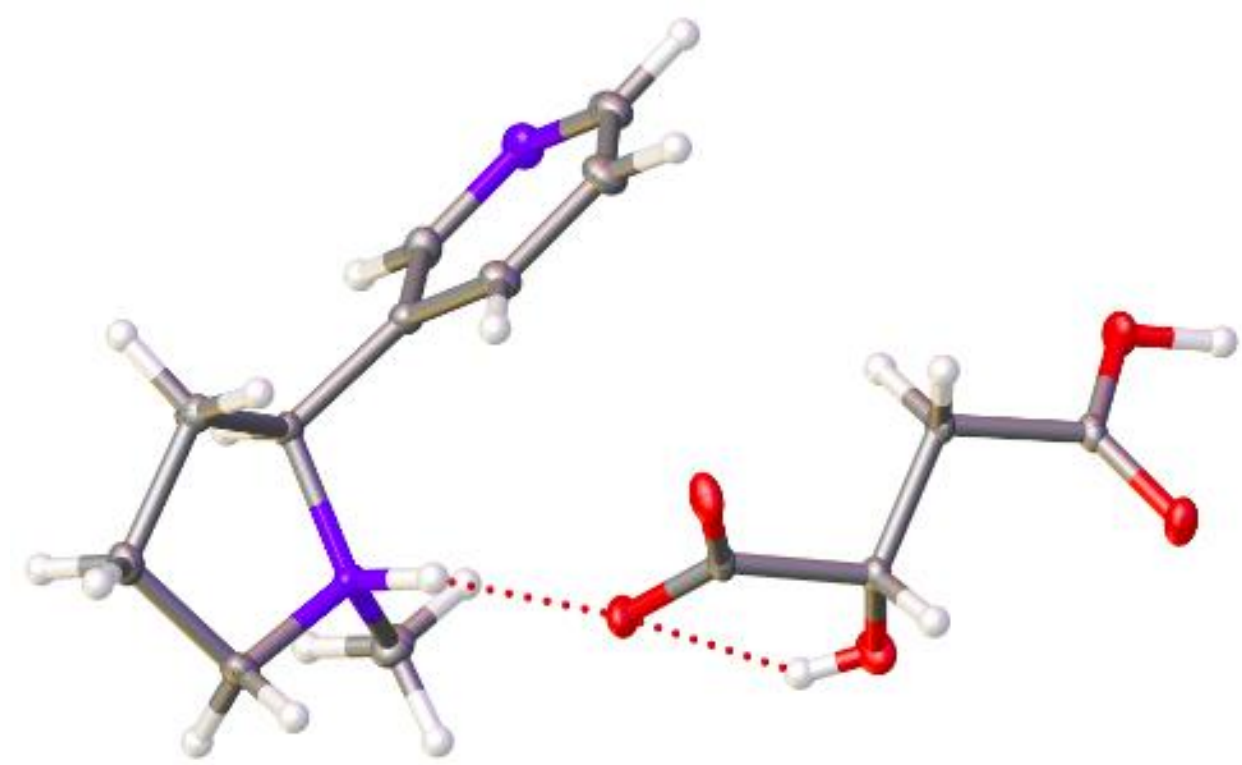

Figure S3: Asymmetric unit of orthorhombic $P 2{ }_{1} 2{ }_{1} 2_{1}(\mathrm{~S})$-nicotinium L-malate. Atom colors: oxygen (red), nitrogen (blue), carbon (grey), hydrogen (white). Hydrogen bond interactions highlighted in red dashed lines. 


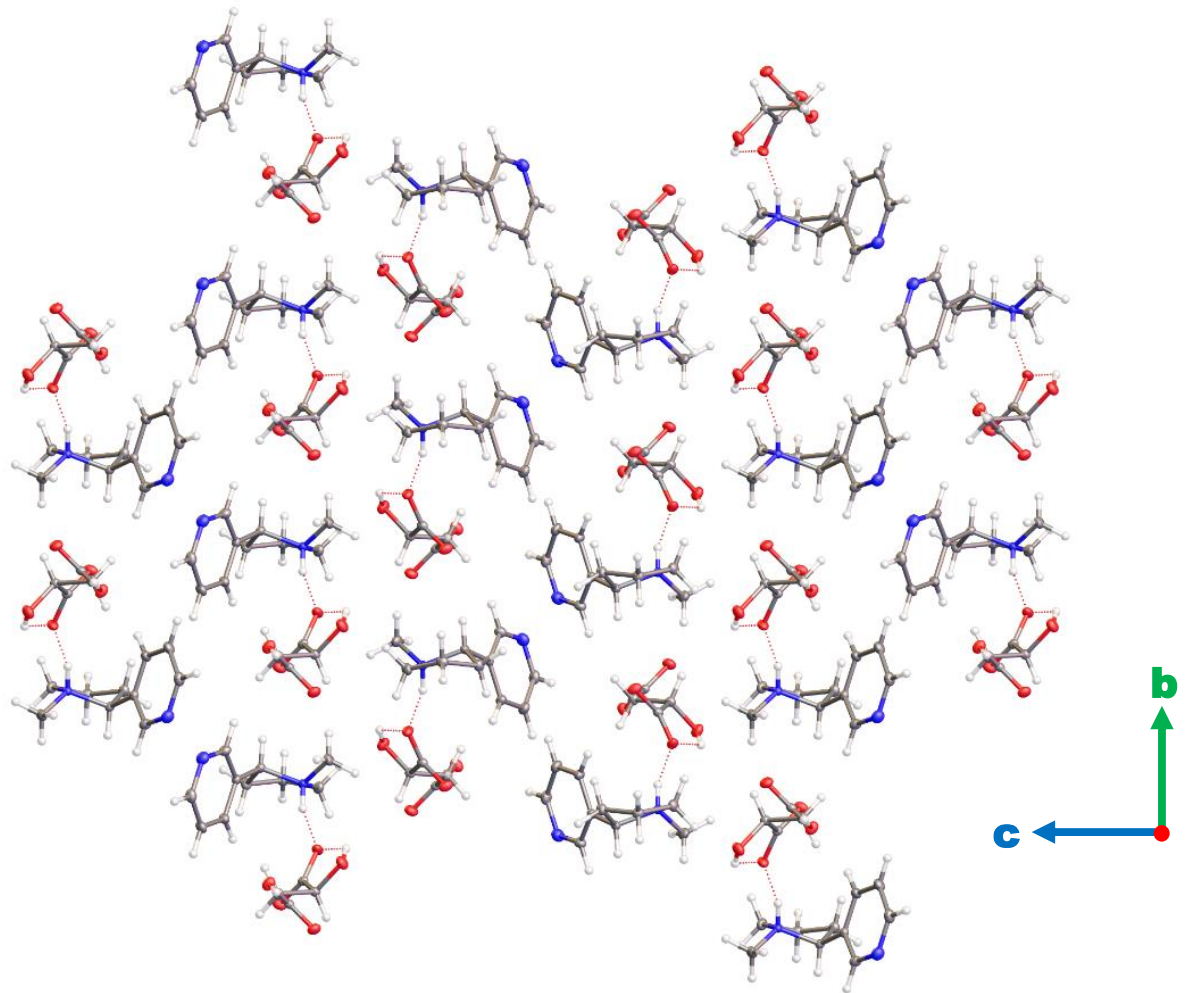

Figure S4: View down crystallographic $a$ - axis of Salt 1 with $b$ and $c$ normal to the plane. Atom colors: oxygen (red), nitrogen (blue), carbon (grey), hydrogen (white). Hydrogen bond interactions highlighted in red dashed lines.

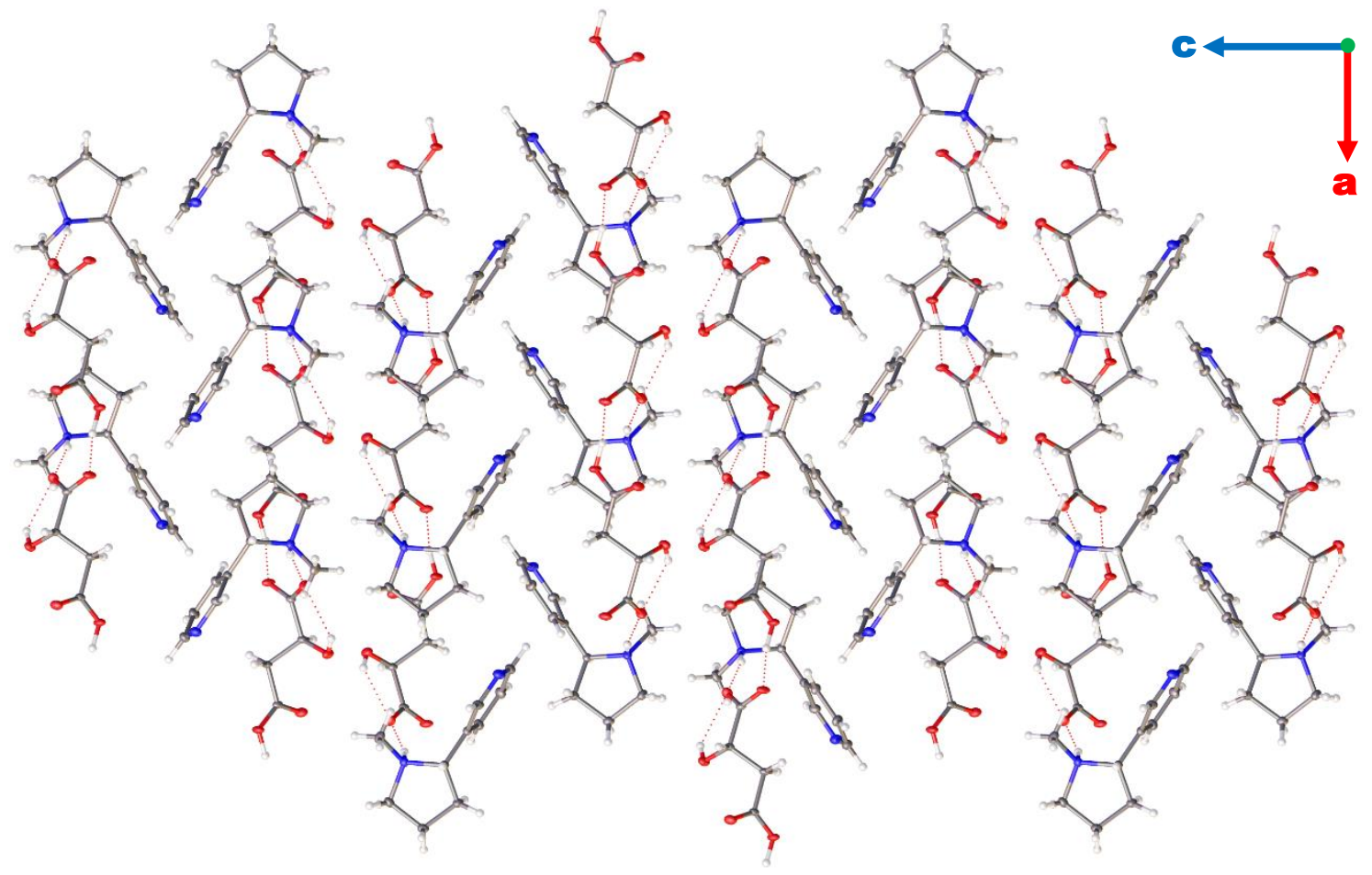

Figure S5: View down crystallographic $b$ - axis of Salt 1 with $a$ and $c$ normal to the plane. Atom colors: oxygen (red), nitrogen (blue), carbon (grey), hydrogen (white). Hydrogen bond interactions highlighted in red dashed lines. 


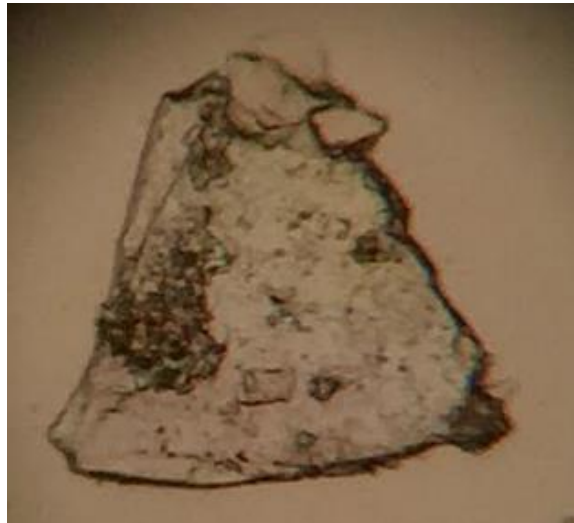

Figure S6: A crystal of monoclinic $P 2_{1}(\mathrm{~S})$-nicotinium L-malate.

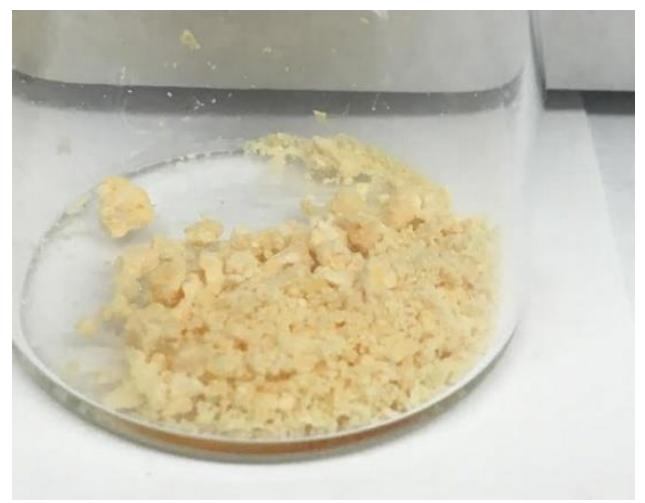

Figure S7: A vial of crystals of monoclinic $P 2_{1}$ (S)-nicotinium L-malate.

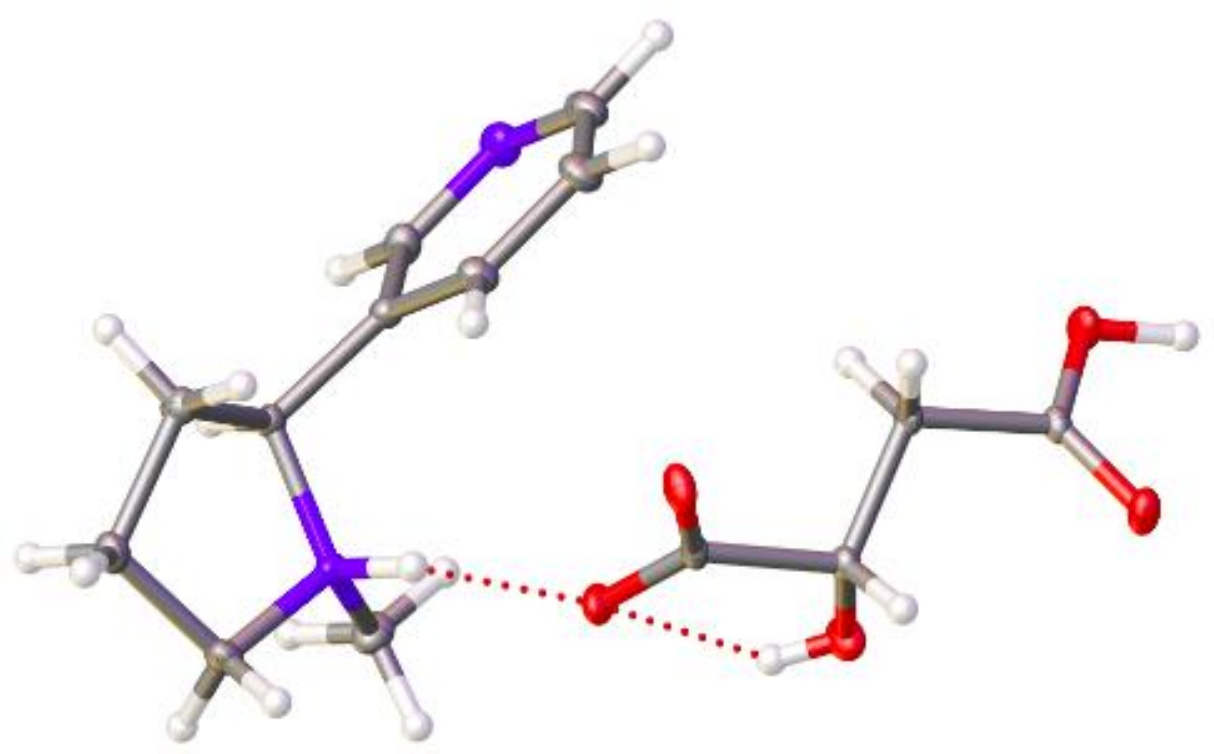

Figure S8: Asymmetric unit of monoclinic $P 2_{1}(\mathrm{~S})$-nicotinium L-malate. Atom colors: oxygen (red), nitrogen (blue), carbon (grey), hydrogen (white). Hydrogen bond interactions highlighted in red dashed lines. 


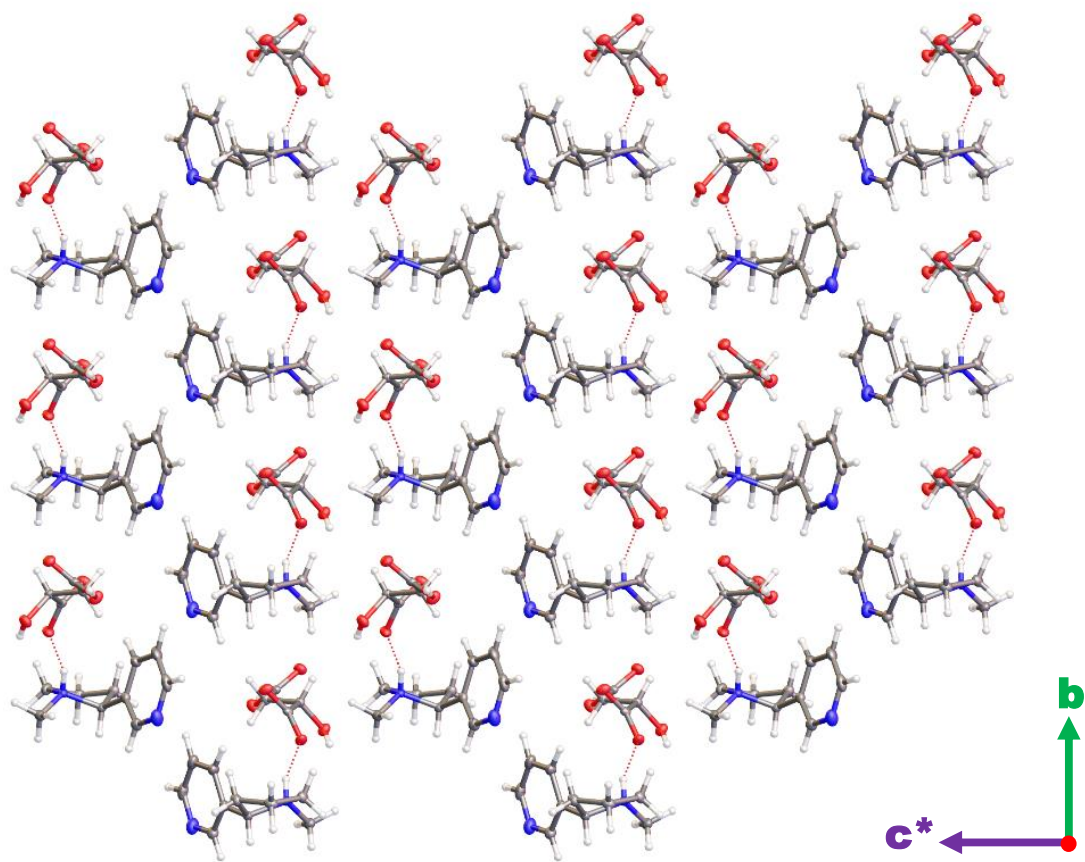

Figure S9: View down crystallographic $a$ - axis of Salt 2 with $b$ and $c^{*}$ normal to the plane. Atom colors: oxygen (red), nitrogen (blue), carbon (grey), hydrogen (white). Hydrogen bond interactions highlighted in red dashed lines.

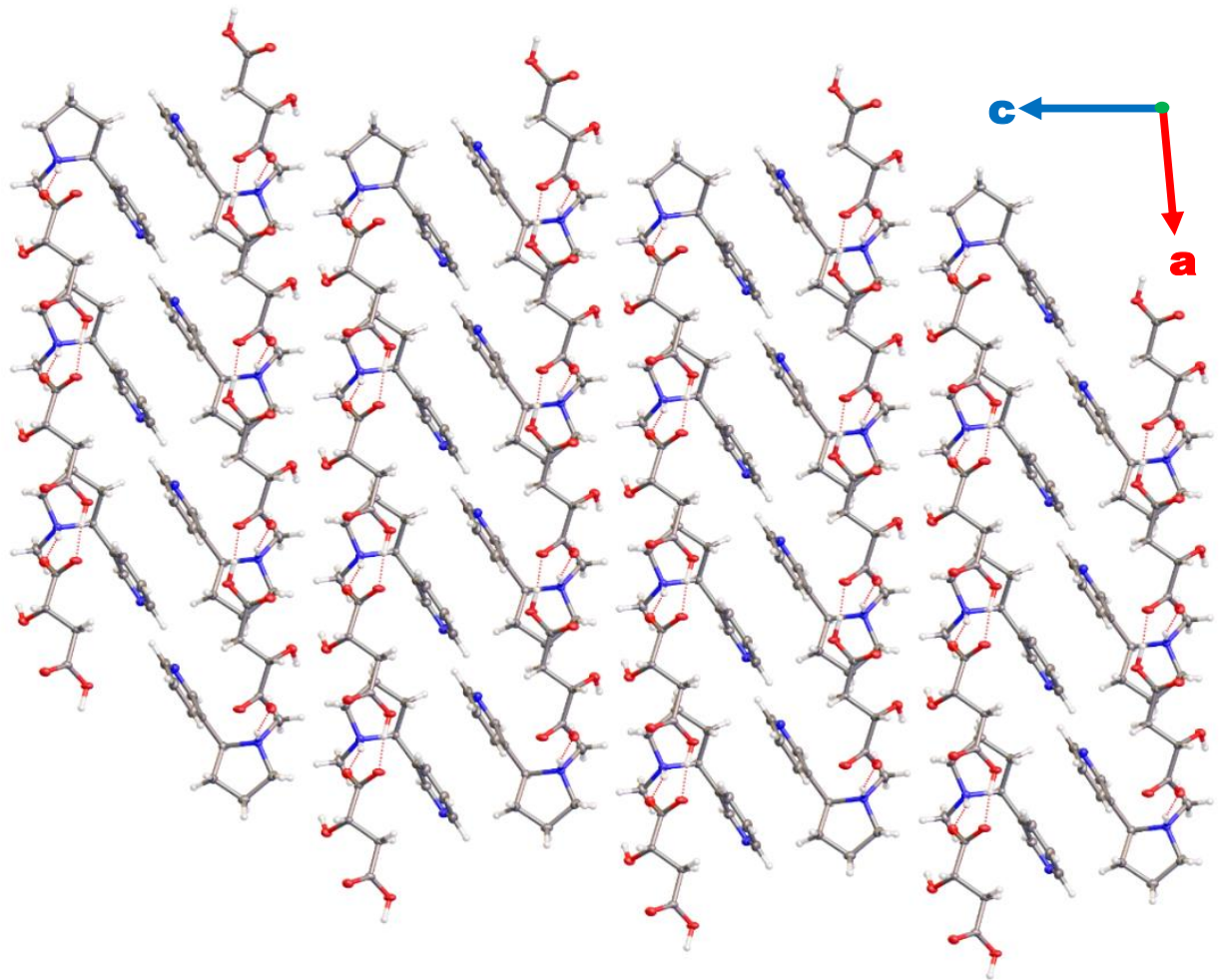

Figure S10: View down crystallographic $b$ - axis of Salt 2 with $a$ and $c$ normal to the plane. Atom colors: oxygen (red), nitrogen (blue), carbon (grey), hydrogen (white). Hydrogen bond interactions highlighted in red dashed lines. 
Salt 3 - Orthorhombic P212121 (S)-Nicotinium D-Malate

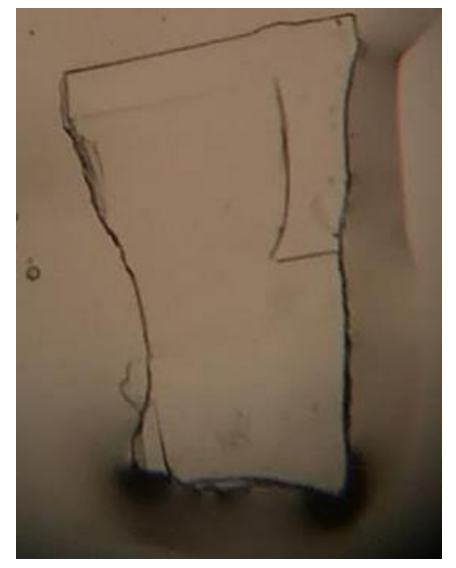

Figure S11: A crystal of orthorhombic $P 2{ }_{1} 2_{1} 2_{1}(\mathrm{~S})$ nicotinium D-malate.

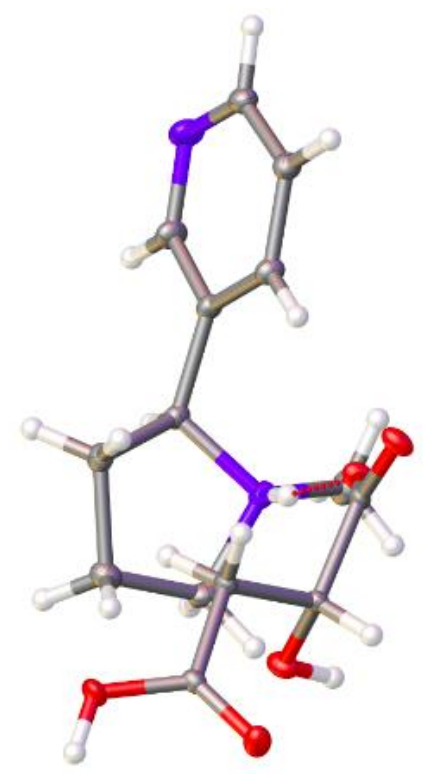

Figure S13

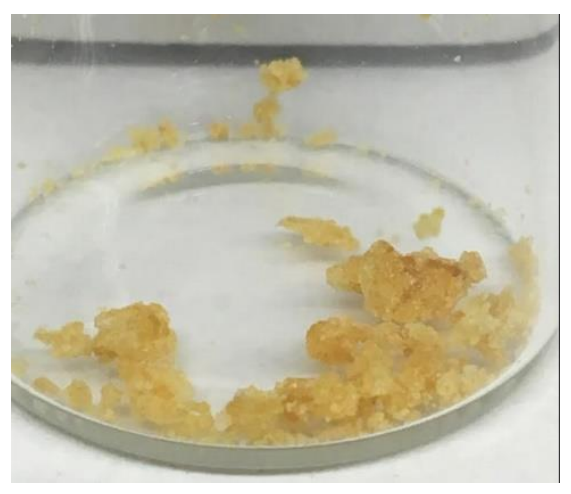

Figure S12: A vial of crystals of orthorhombic $P 2{ }_{1} 2_{1} 2_{1}$ (S)nicotinium D-malate.

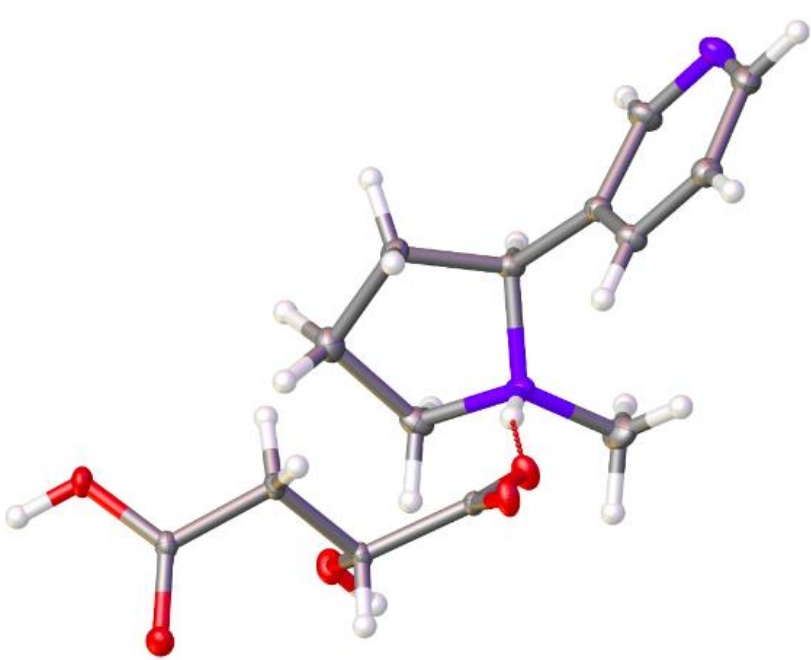

Figure S14

Figure S13 \& S14: Asymmetric unit of orthorhombic $P 2{ }_{1} 2_{1} 2_{1}(\mathrm{~S})$-nicotinium D-malate. Atom colors: oxygen (red), nitrogen (blue), carbon (grey), hydrogen (white). Hydrogen bond interactions highlighted in red dashed lines. 


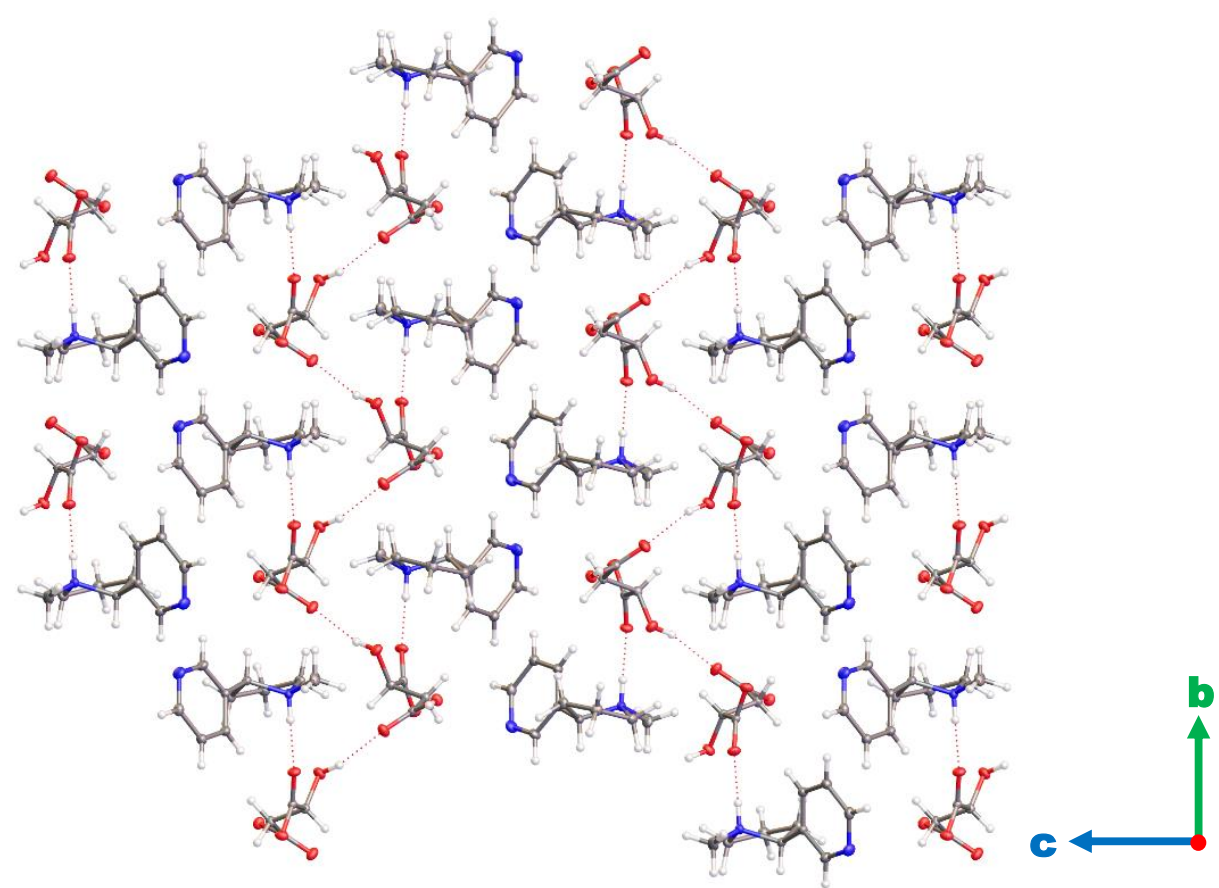

Figure S15: View down crystallographic $a$ - axis of Salt 3 with $b$ and $c$ normal to the plane. Atom colors: oxygen (red), nitrogen (blue), carbon (grey), hydrogen (white). Hydrogen bond interactions highlighted in red dashed lines.

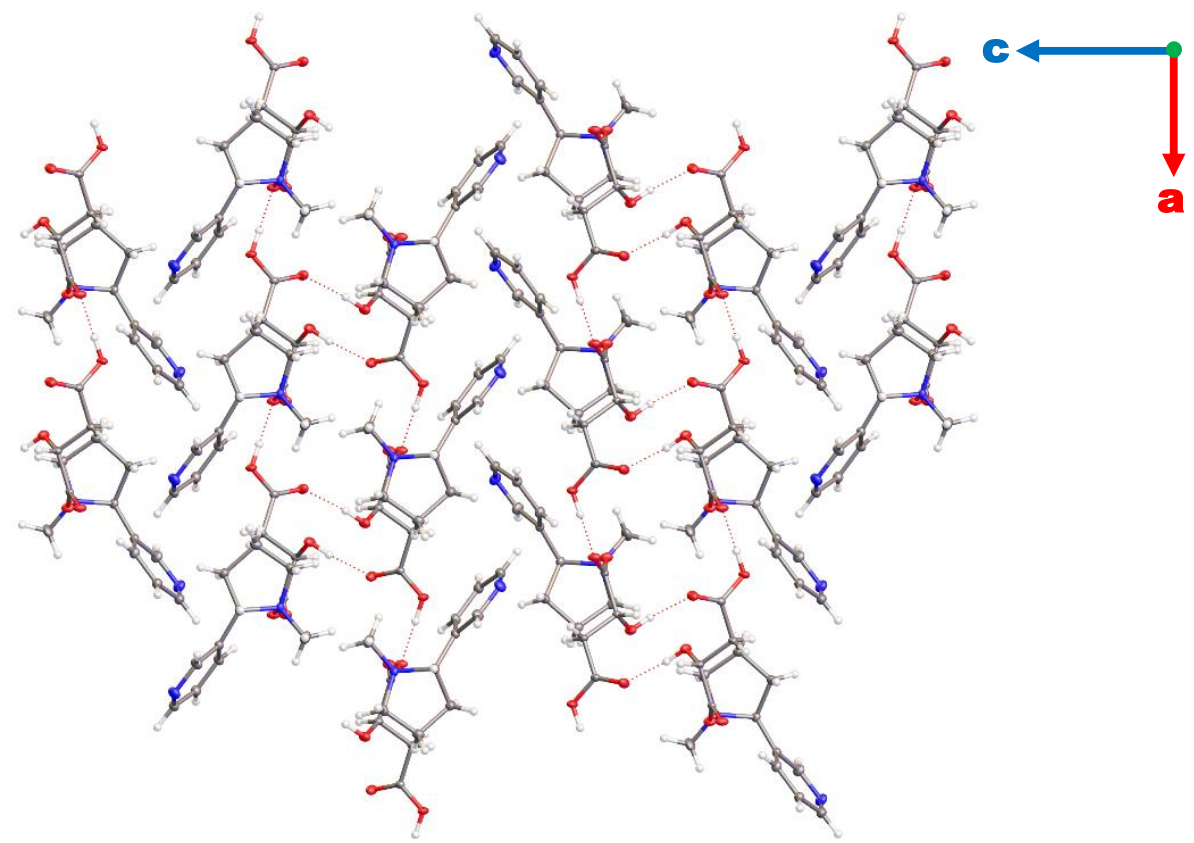

Figure S16: View down crystallographic $b$ - axis of Salt 3 with $a$ and $c$ normal to the plane. Atom colors: oxygen (red), nitrogen (blue), carbon (grey), hydrogen (white). Hydrogen bond interactions highlighted in red dashed lines. 


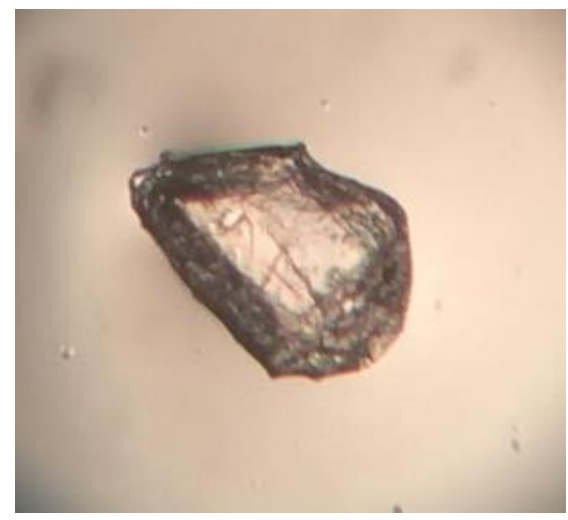

Figure S17: A crystal of orthorhombic $P 22_{1} 2_{1} \quad(\mathrm{~S})$ nicotinium DL-malate.

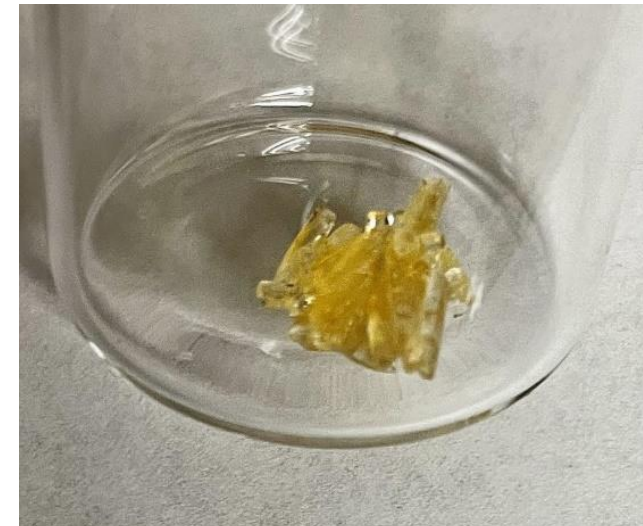

Figure S18: A vial of crystals of orthorhombic $\quad P 212121$

$(\mathrm{S})$ -

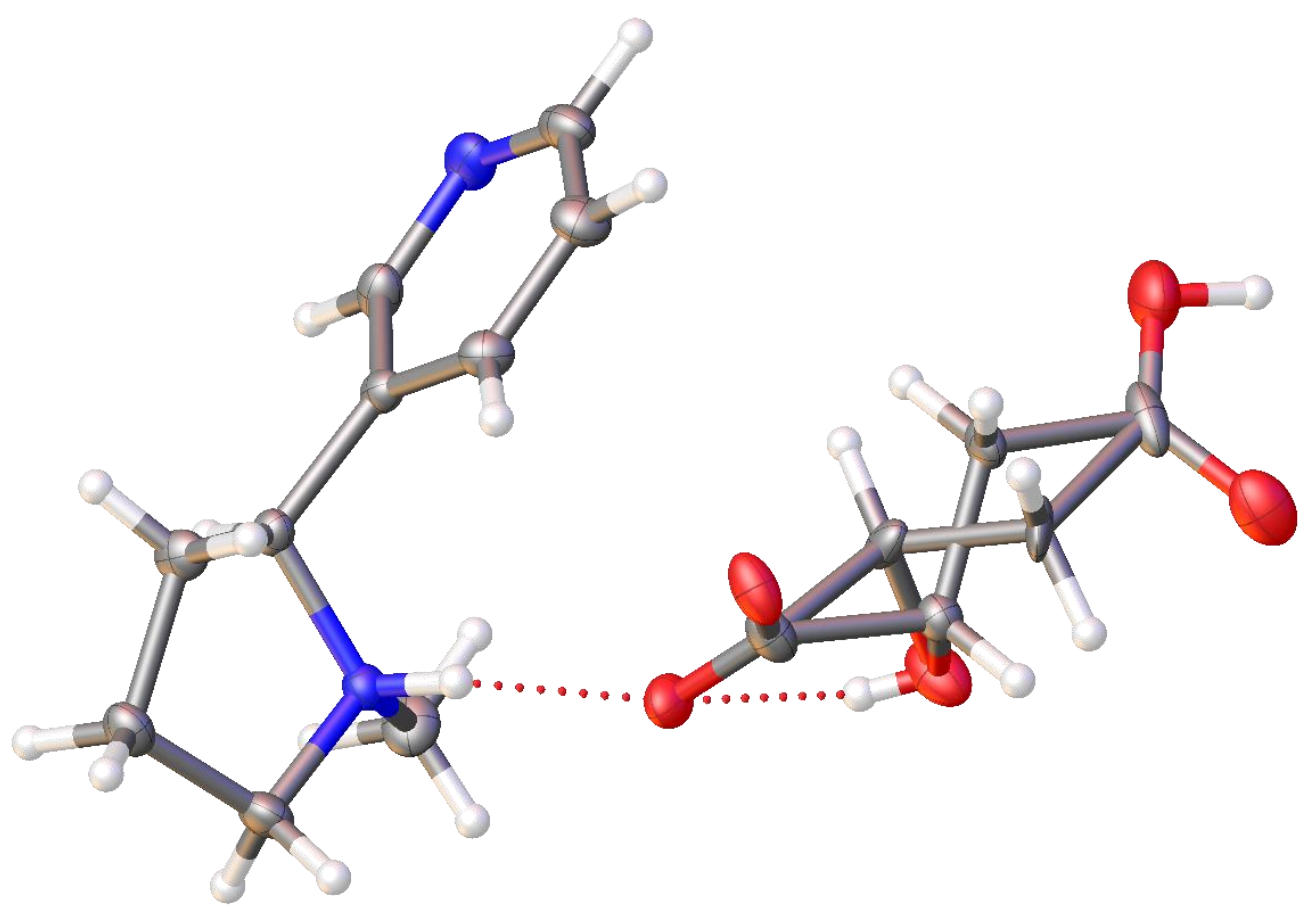

Figure S19: Asymmetric unit of orthorhombic P2 $2_{1} 2_{1} 2_{1}$ (S)-nicotinium DL-malate. Atom colors: oxygen (red), nitrogen (blue), carbon (grey), hydrogen (white). Hydrogen bond interactions highlighted in red dashed lines. 


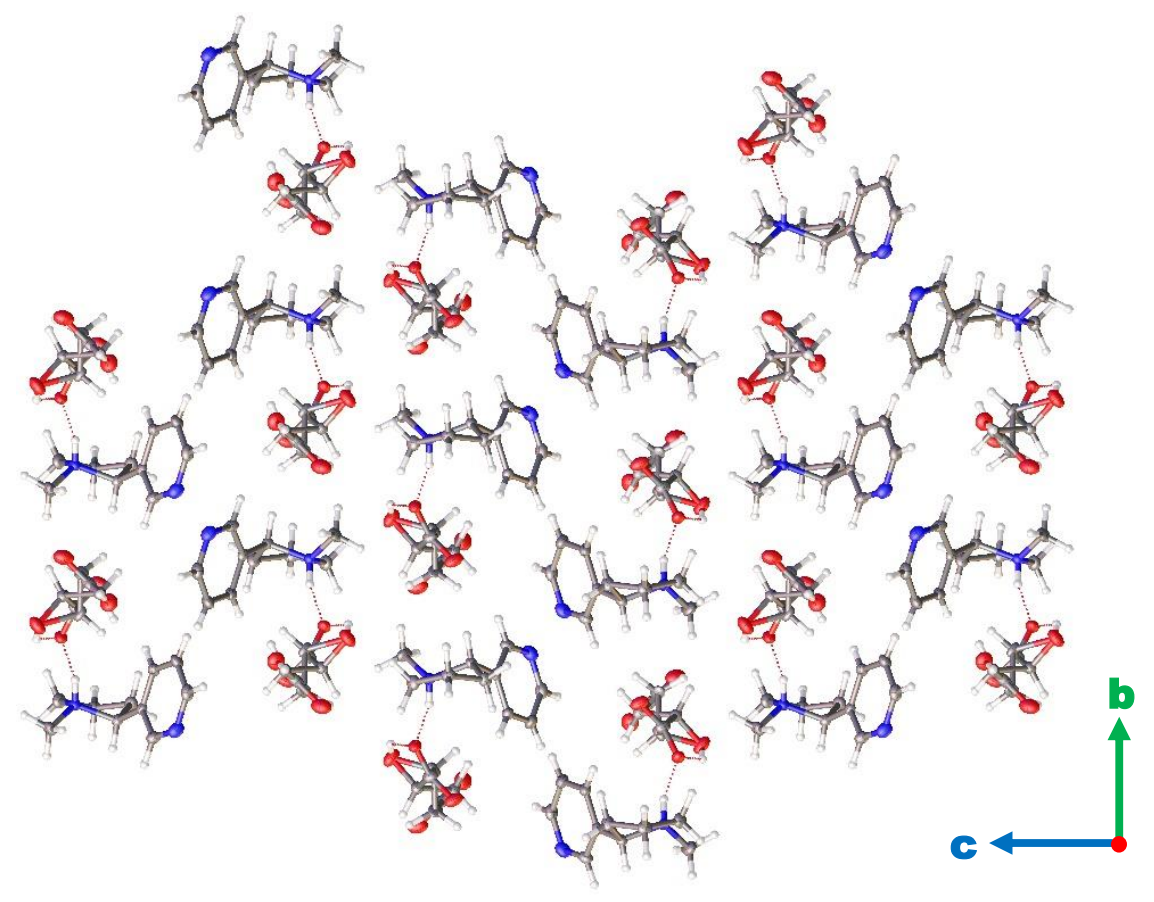

Figure S20: View down crystallographic $a$ - axis of Salt 4 with $b$ and $c$ normal to the plane. Atom colors: oxygen (red), nitrogen (blue), carbon (grey), hydrogen (white). Hydrogen bond interactions highlighted in red dashed lines.

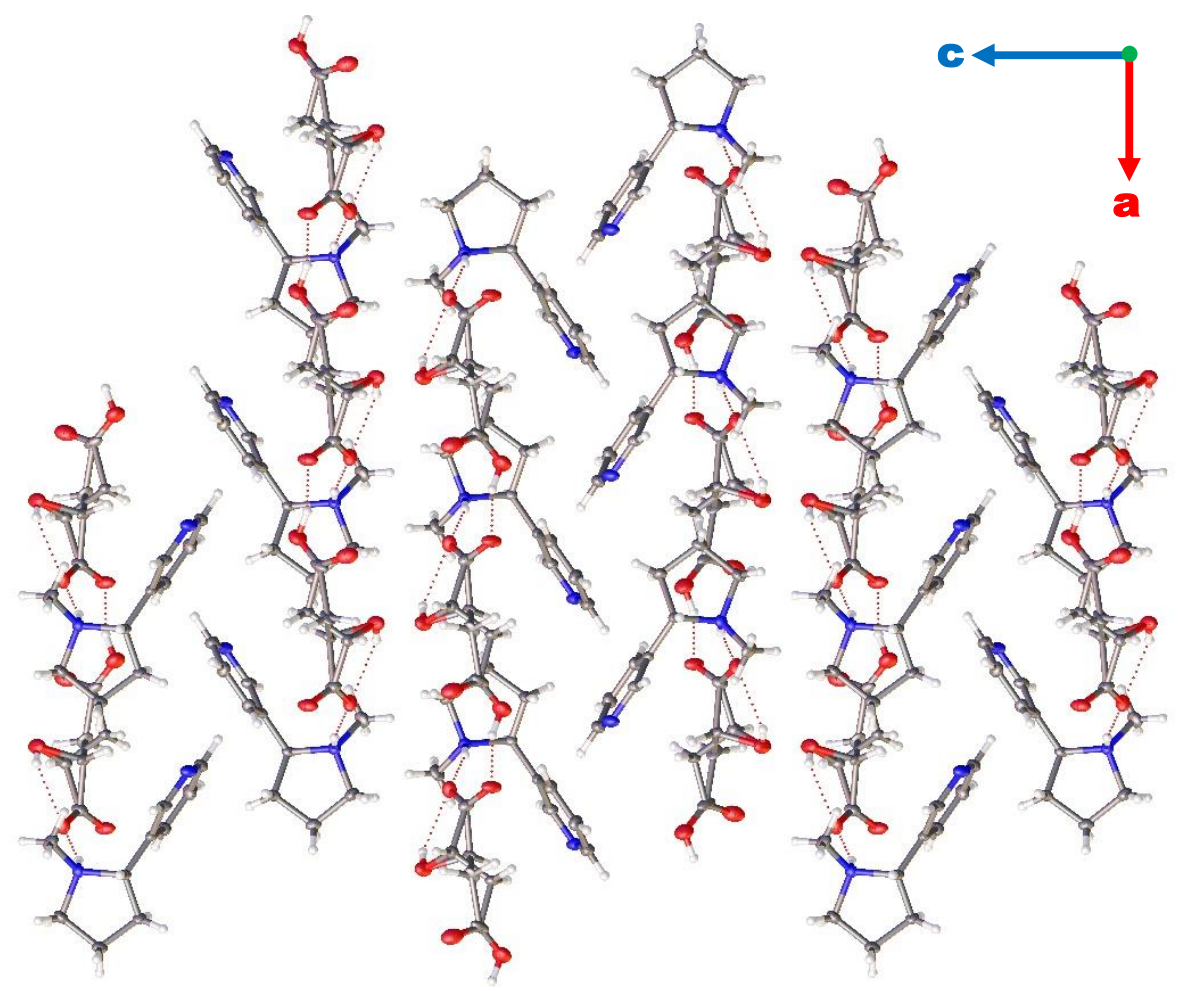

Figure S21: View down crystallographic $b$ - axis of Salt 4 with $a$ and $c$ normal to the plane. Atom colors: oxygen (red), nitrogen (blue), carbon (grey), hydrogen (white). Hydrogen bond interactions highlighted in red dashed lines. 
In the case of Salt 4, the initial solution produced the positions of the carbon, nitrogen and oxygen atoms for the S-nicotinium cation and the major observed malate enantiomer. Upon refinement, q-peaks corresponding to the hydrogen atom positions were observed as well as two additional q-peaks near $\mathrm{C} 12 \mathrm{~A}$ and $\mathrm{C} 13 \mathrm{~A}$ of the malate. These atoms were subsequently split and the resulting atoms $\mathrm{C} 12 \mathrm{~B}$ and $\mathrm{C} 13 \mathrm{~B}$ were freely refined, albeit with the constraint that the occupancy of the disordered A/B pairs summed to 1.0. The occupancies of the pairs refined to 80.8(15):19.2(15) for carbon A and 80.6(12):19.4(12) for carbon B which confirms the corresponding pairs each belong to a common malate anion. Using a common FVAR command, the occupancies of carbon atoms and their attached protons refined to $17.8(8) \%$ and 82.2(8)\% D-malate and L-malate, respectively.

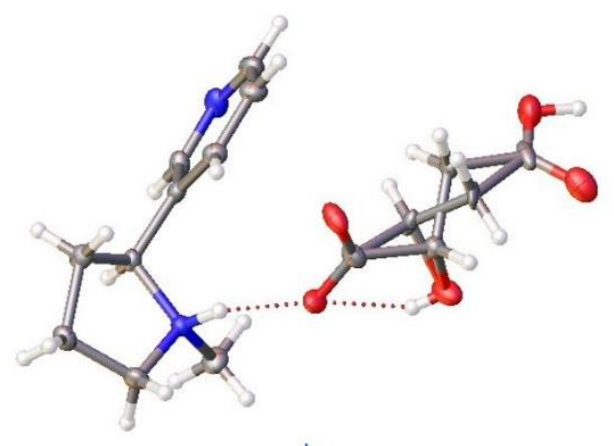

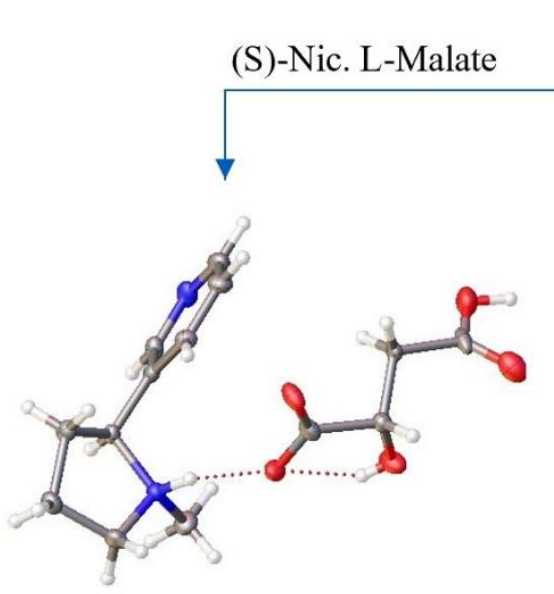

$82.2(8) \%$ occupancy within the lattice
(S)-Nic. D-Malate

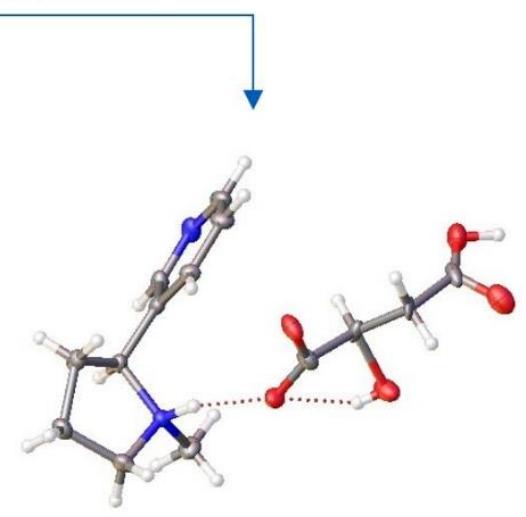

$17.8(8) \%$ occupancy within the lattice

Figure S22: Diagram of lattice distribution among the salt former enantiomers in Salt 4. Atom colors: oxygen (red), nitrogen (blue), carbon (grey), hydrogen (white). Hydrogen bonding interactions are depiected in red dashed lines. 


\section{Hydrogen Bonding Interaction Tables}

Table S2: Salt 1 Hydrogen bonding interactions and the associated estimated standard deviations (esds). Symmetry equivalent atoms are included and noted in the interacting atoms list.

\begin{tabular}{|c|c|c|c|c|}
\hline D-H (A) & H....A $(\AA)$ & D...A (A) & $<($ DHA $)\left(^{\circ}\right)$ & Interacting Atoms \\
\hline $0.904(18)$ & $1.846(18)$ & $2.7055(11)$ & $158.0(16)$ & N2-H2...O2 \\
\hline $0.966(18)$ & $2.521(18)$ & $3.2225(13)$ & $129.5(14)$ & C8-H8A...O4_\$1 \\
\hline $0.998(17)$ & $2.607(16)$ & $3.5589(13)$ & $159.4(13)$ & C9-H9B...O2_\$2 \\
\hline $0.998(17)$ & $2.654(18)$ & $3.2243(13)$ & $116.4(11)$ & C9-H9B...O4_\$1 \\
\hline $0.98(2)$ & $2.56(2)$ & $3.2040(11)$ & $123.5(15)$ & O3-H3A...O2_\$3 \\
\hline $0.98(2)$ & $1.55(2)$ & $2.5194(10)$ & $169(2)$ & O3-H3A...O1_\$3 \\
\hline $0.978(18)$ & $2.483(18)$ & $3.4093(13)$ & $158.0(15)$ & C5-H5...O1_\$4 \\
\hline $0.94(2)$ & $2.64(2)$ & $3.4411(13)$ & $143.5(15)$ & C10-H10A...O4_\$1 \\
\hline $0.987(16)$ & $2.431(17)$ & $3.3831(13)$ & $161.9(14)$ & C10-H10B...O4_\$5 \\
\hline $0.970(17)$ & $2.636(17)$ & $3.4630(13)$ & $143.5(13)$ & C7-H7A...O3_\$6 \\
\hline $0.74(2)$ & $2.10(2)$ & $2.6005(11)$ & $125(2)$ & O5-H5A...O2 \\
\hline
\end{tabular}

Table S3: Salt 2 Hydrogen bonding interactions and the associated estimated standard deviations (esds). Symmetry equivalent atoms are included in the interacting atoms list.

\begin{tabular}{|c|c|c|c|c|}
\hline D-H (̊̊) & H...A (̊̊) & D...A (̊) & $<($ DHA $)\left(^{\circ}\right)$ & Interacting Atoms \\
\hline $1.00(2)$ & $2.62(2)$ & $3.506(2)$ & $146.6(15)$ & C7-H7A...O3_\$1 \\
\hline $0.95(3)$ & $2.45(2)$ & $3.335(2)$ & $155.5(19)$ & C5-H5...O1_\$2 \\
\hline $0.95(3)$ & $2.62(3)$ & $3.542(2)$ & 163(2) & C9-H9B...O2_\$3 \\
\hline $0.88(3)$ & $1.85(3)$ & $2.6863(18)$ & $159(2)$ & N2-H2...O2 \\
\hline $0.89(3)$ & $2.03(3)$ & $2.6099(18)$ & $122(2)$ & O5-H5A...O2 \\
\hline $1.04(3)$ & $2.56(3)$ & $3.266(2)$ & $125.1(18)$ & C8-H8B...O4_\$4 \\
\hline $0.97(3)$ & $1.55(3)$ & $2.5155(17)$ & $174(3)$ & O3-H3A...O1_\$5 \\
\hline $0.97(3)$ & $2.64(3)$ & $3.2489(18)$ & $122(2)$ & O3-H3A...O2_\$5 \\
\hline $0.94(3)$ & $2.60(3)$ & $3.423(2)$ & $147(2)$ & C10-H10B...O4_\$4 \\
\hline $1.02(2)$ & $2.36(3)$ & $3.371(2)$ & $166.8(19)$ & C10-H10C...O4_\$6 \\
\hline
\end{tabular}


Table S4: Salt 3 Hydrogen bonding interactions and the associated estimated standard deviations (esds). Symmetry equivalent atoms are included in the interacting atoms list.

\begin{tabular}{|c|c|c|c|c|}
\hline $\mathbf{D}-\mathbf{H}(\AA)$ & $\mathbf{H} . . . \mathbf{A}(\AA)$ & $\mathbf{D} \ldots \mathbf{A}(\AA)$ & $<(\mathbf{D H A})\left(^{\circ}\right)$ & Interacting Atoms \\
\hline $1.00(2)$ & $2.40(2)$ & $3.3451(15)$ & $158.2(16)$ & C9-H9A...O4_\$1 \\
\hline $0.982(17)$ & $2.464(17)$ & $3.3724(14)$ & $153.6(14)$ & C6-H6...O1_\$2 \\
\hline $0.98(2)$ & $2.52(2)$ & $3.3884(17)$ & $147.3(18)$ & C10-H10C...O1_\$2 \\
\hline $0.901(18)$ & $1.814(18)$ & $2.7019(13)$ & $168.1(18)$ & N2-H2...O2 \\
\hline $0.90(3)$ & $1.63(3)$ & $2.5314(12)$ & $177(3)$ & O3-H3A...O1_\$3 \\
\hline $0.90(3)$ & $2.65(3)$ & $3.1988(12)$ & $120(2)$ & O3-H3A...O2_\$3 \\
\hline $0.86(2)$ & $2.08(2)$ & $2.9120(13)$ & $163.1(18)$ & O5-H5A...O4_\$1 \\
\hline
\end{tabular}

Table S5: Salt 4 Hydrogen bonding interactions and the associated estimated standard deviations (esds). Symmetry equivalent atoms are included in the interacting atoms list.

\begin{tabular}{|c|c|c|c|c|}
\hline $\mathbf{D}-\mathbf{H}(\AA)$ & $\mathbf{H} . . . \mathbf{A}(\AA)$ & $\mathbf{D} . . . \mathbf{A}(\AA)$ & $<(\mathbf{D H A})\left(^{\circ}\right)$ & Interacting Atoms \\
\hline $0.90(4)$ & $1.85(4)$ & $2.704(3)$ & $159(3)$ & N2-H2...O2 \\
\hline $0.69(4)$ & $2.11(4)$ & $2.615(3)$ & $131(4)$ & O5-H5A...O2 \\
\hline $1.03(3)$ & $2.49(3)$ & $3.244(3)$ & $130(2)$ & C8-H8A...O4_\$1 \\
\hline $0.98(3)$ & $2.62(3)$ & $3.556(3)$ & $160(3)$ & C9-H9B...O2_\$2 \\
\hline $0.97(3)$ & $2.53(3)$ & $3.463(3)$ & $161(3)$ & C5-H5...O1_\$3 \\
\hline $0.98(4)$ & $2.65(4)$ & $3.462(3)$ & $141(3)$ & C10-H10A...O4_\$1 \\
\hline $0.96(4)$ & $2.46(4)$ & $3.389(3)$ & $161(3)$ & C10-H10B...O4_\$4 \\
\hline $1.00(3)$ & $2.65(3)$ & $3.502(3)$ & $144(2)$ & C7-H7B...O3_\$5 \\
\hline $0.91(2)$ & $2.58(4)$ & $3.191(3)$ & $125(3)$ & O3-H3A...O2_\$6 \\
\hline $0.91(2)$ & $1.64(3)$ & $2.517(3)$ & $161(4)$ & O3-H3A...O1_\$6 \\
\hline
\end{tabular}




\section{DSC Multiple Scans for Salts 1-4}

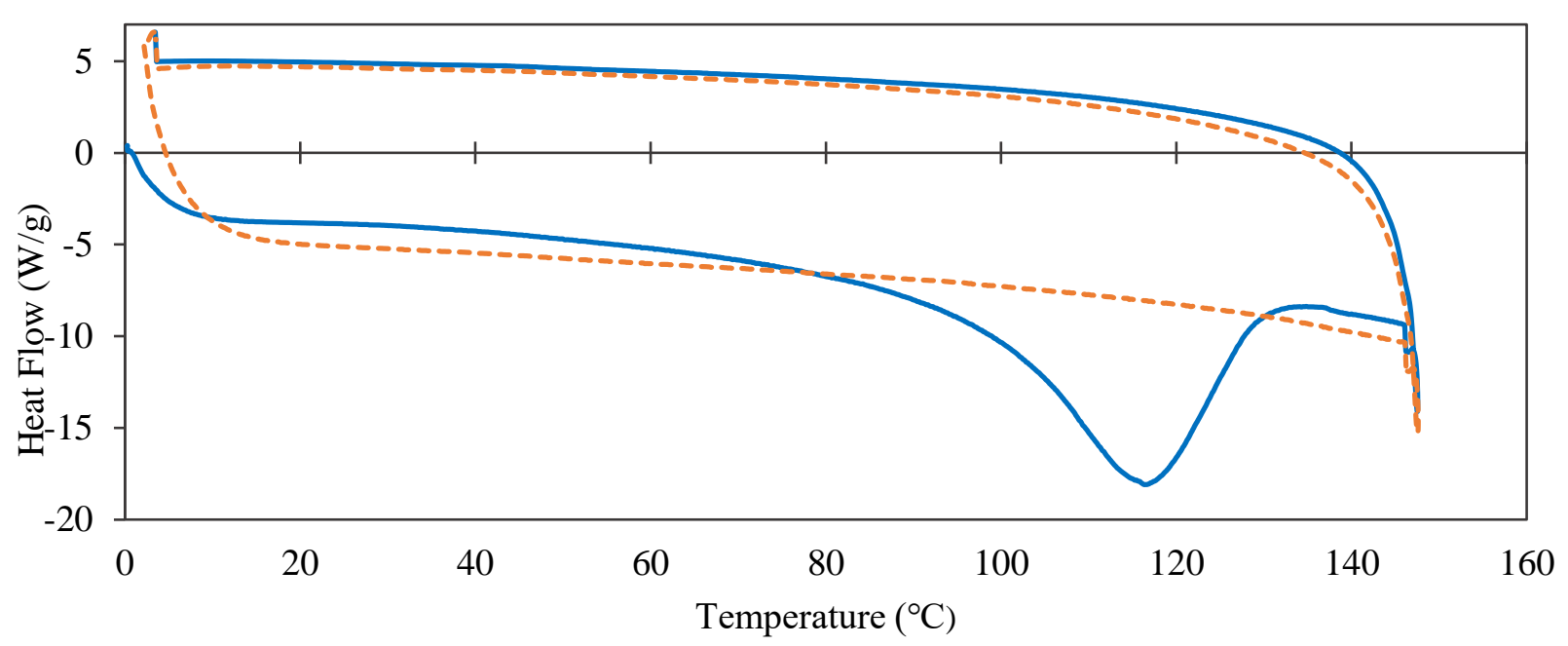

Figure S23A: Multiple DSC scans for Salt 1 depicting the lack of recrystallization and the lack of sharp endotherms after the melting in the initial scan. The first cycle is depicted in solid blue, while the second cycle is highlighted in dashed orange.

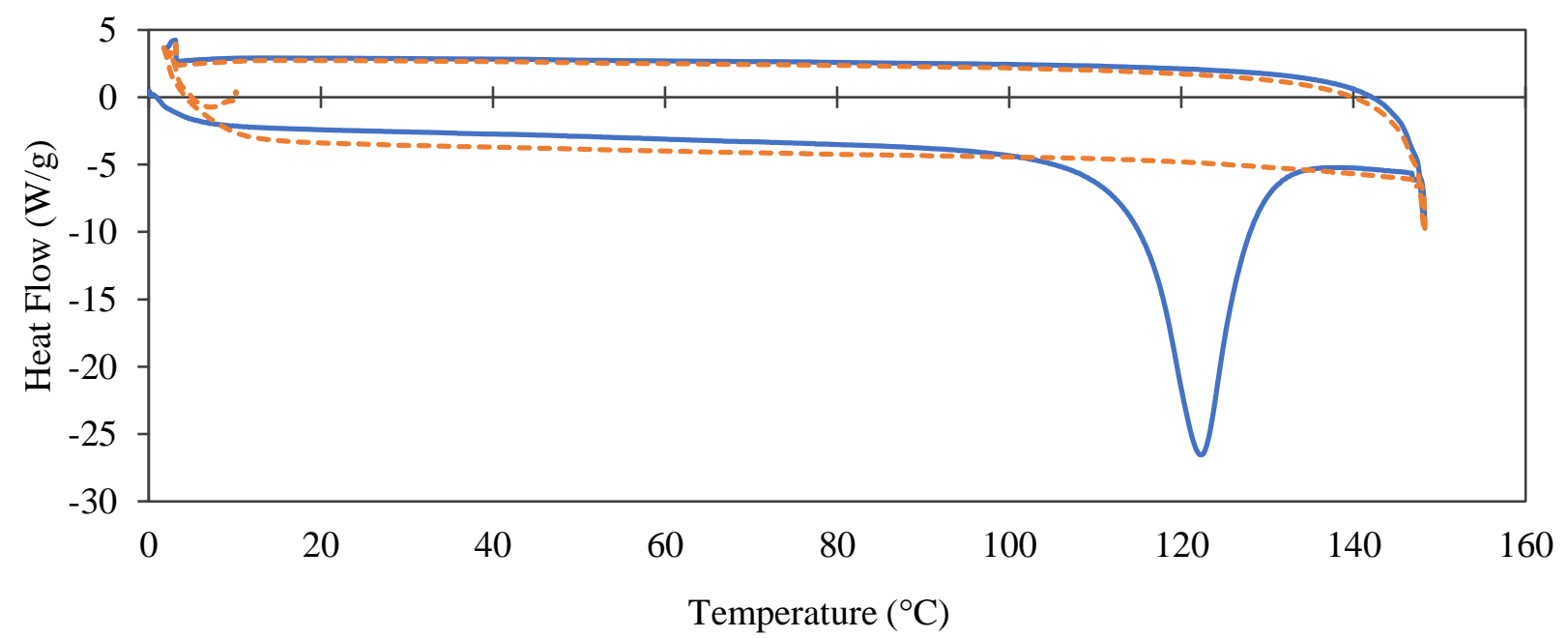

Figure S23B: Multiple DSC scans for Salt 2 depicting the lack of recrystallization and the lack of sharp endotherms after the melting in the initial scan. The first cycle is depicted in solid blue, while the second cycle is highlighted in dashed orange. 


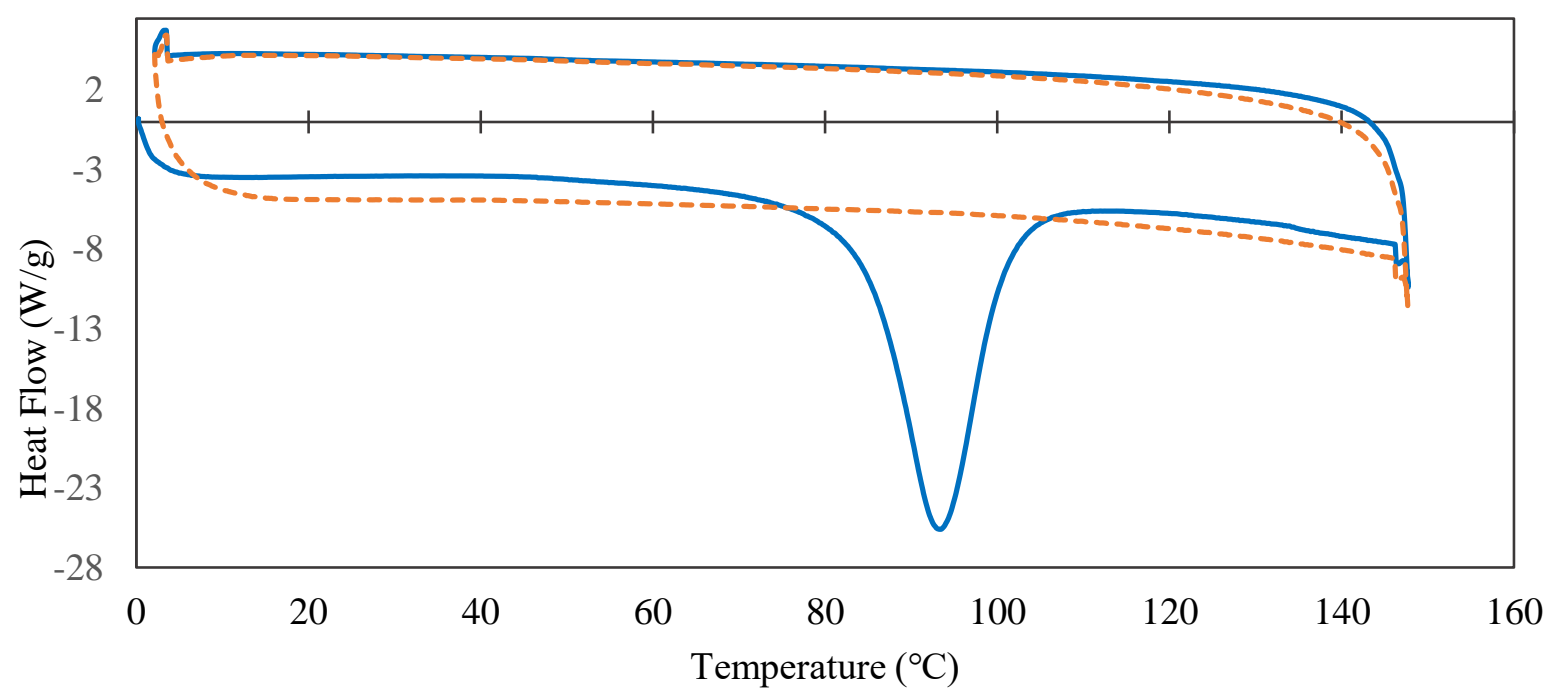

Figure S23C:Multiple DSC scans for Salt 3 depicting the lack of recrystallization and the lack of sharp endotherms after the melting in the initial scan. The first cycle is depicted in solid blue, while the second cycle is highlighted in dashed orange.

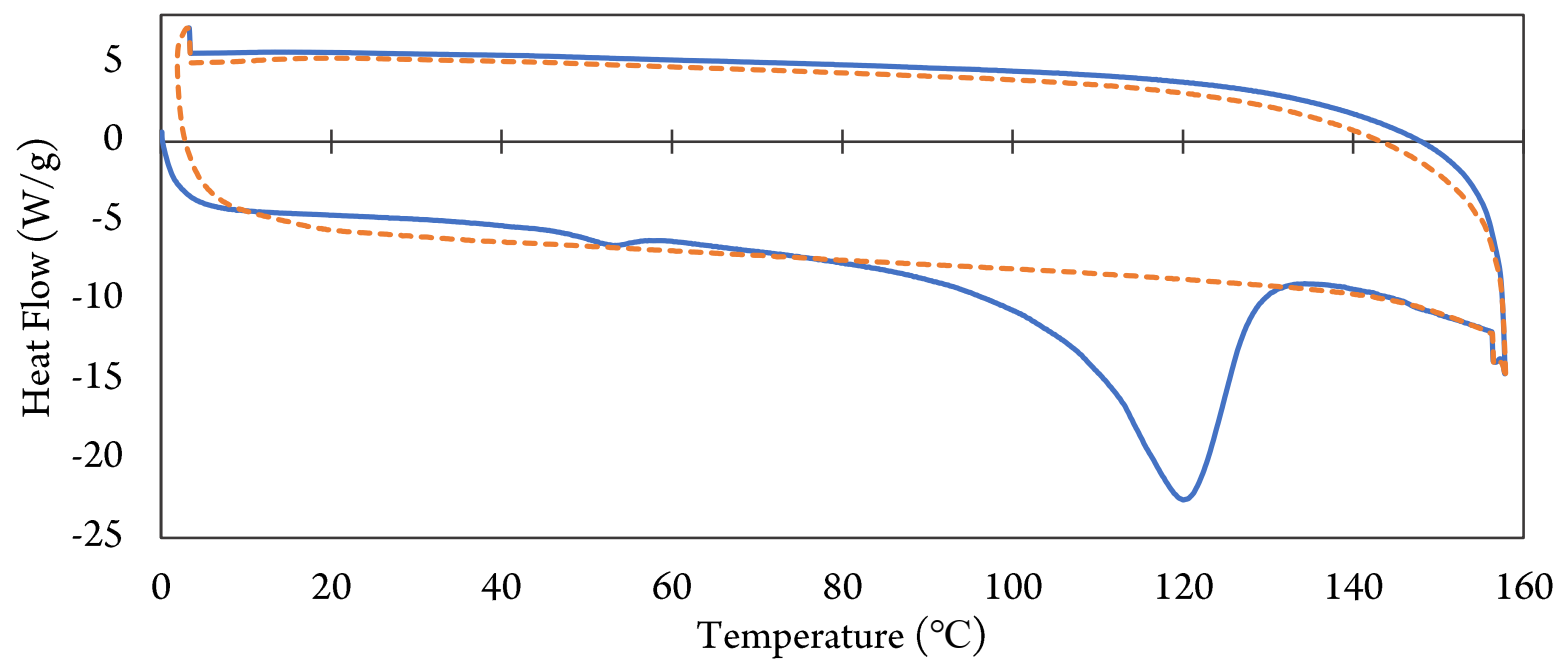

Figure S23D:Multiple DSC scans for Salt 4 depicting the lack of recrystallization and the lack of sharp endotherms after the melting in the initial scan. The first cycle is depicted in solid blue, while the second cycle is highlighted in dashed orange. 


\section{UV Degradation Studies}

\section{Salt Former ${ }^{1}$ H-NMR Spectra}

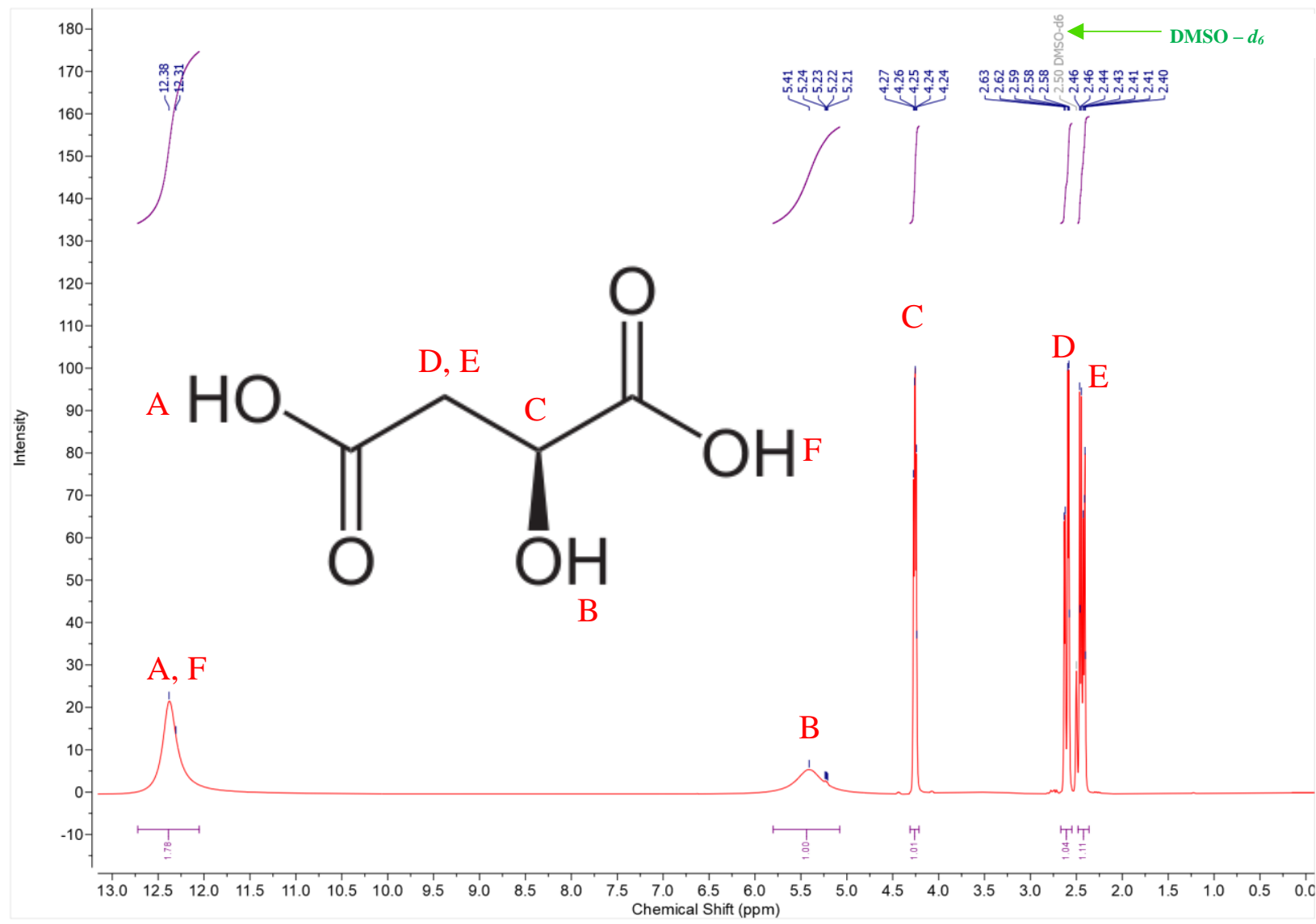

Figure S24: ${ }^{1} \mathrm{H}-\mathrm{NMR}$ spectrum for L-malic acid from the bottle. 


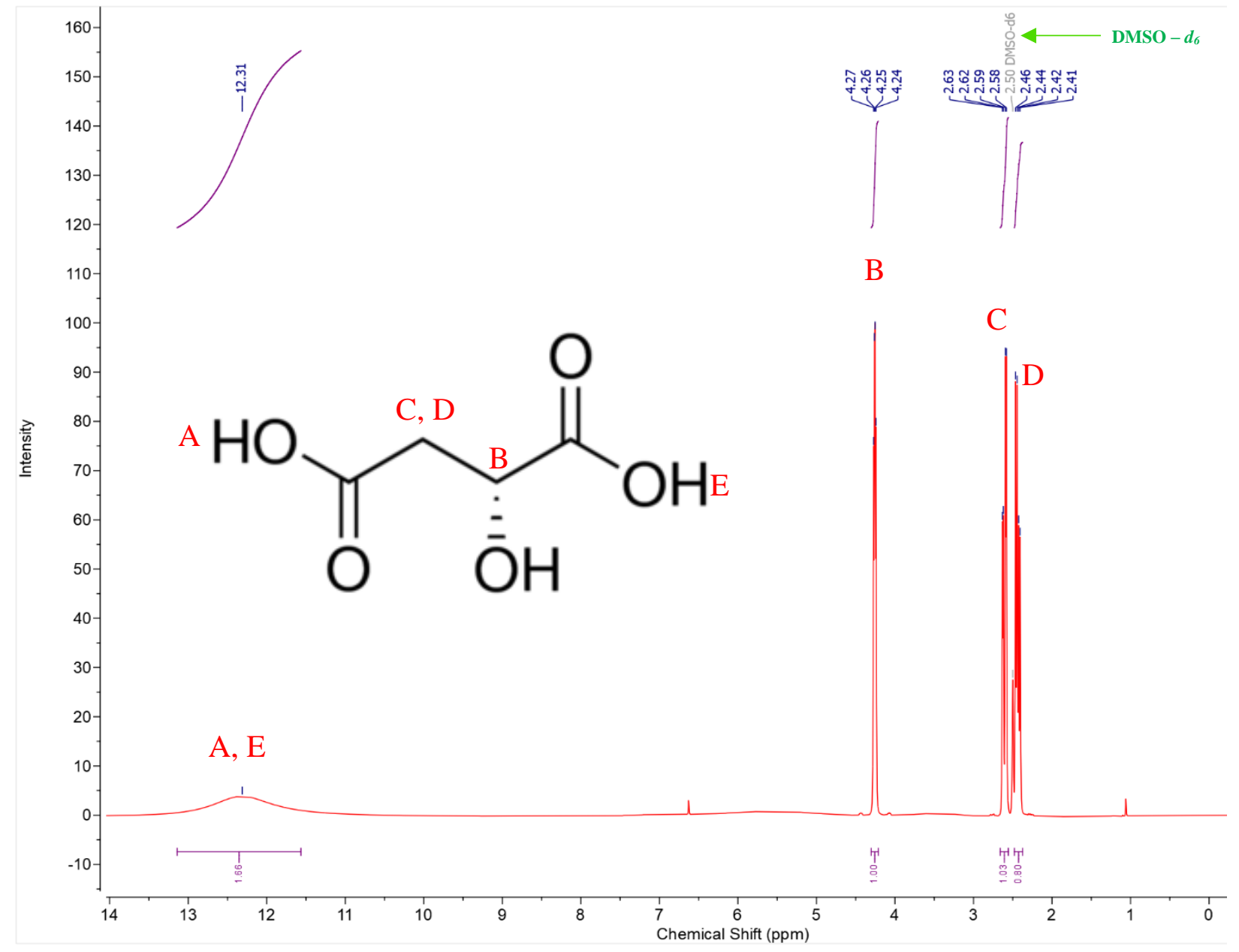

Figure S25: ${ }^{1} \mathrm{H}-\mathrm{NMR}$ spectrum for D-malic acid from the bottle. 


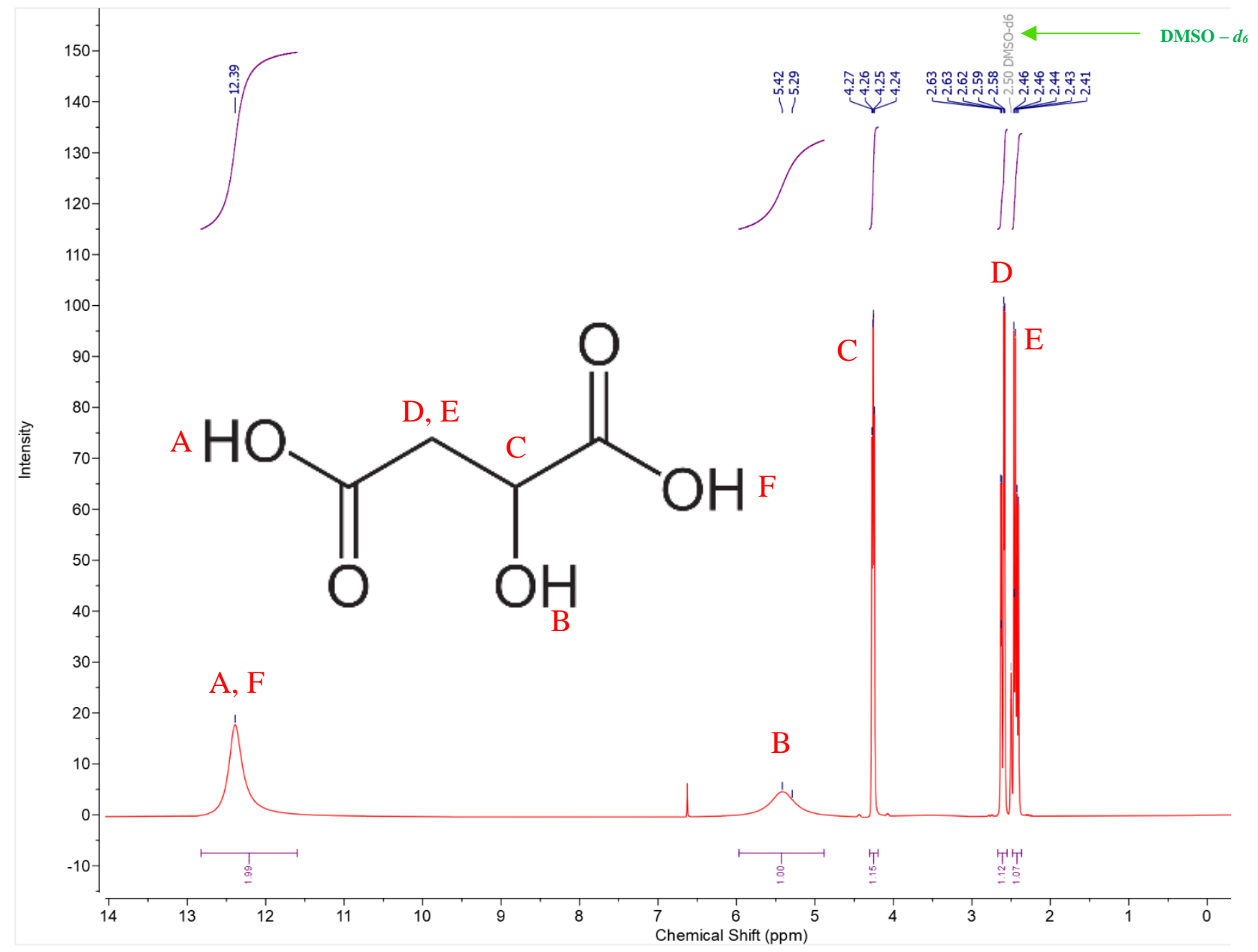

Figure S26: ${ }^{1} \mathrm{H}-\mathrm{NMR}$ spectrum for DL-malic acid from the bottle. 


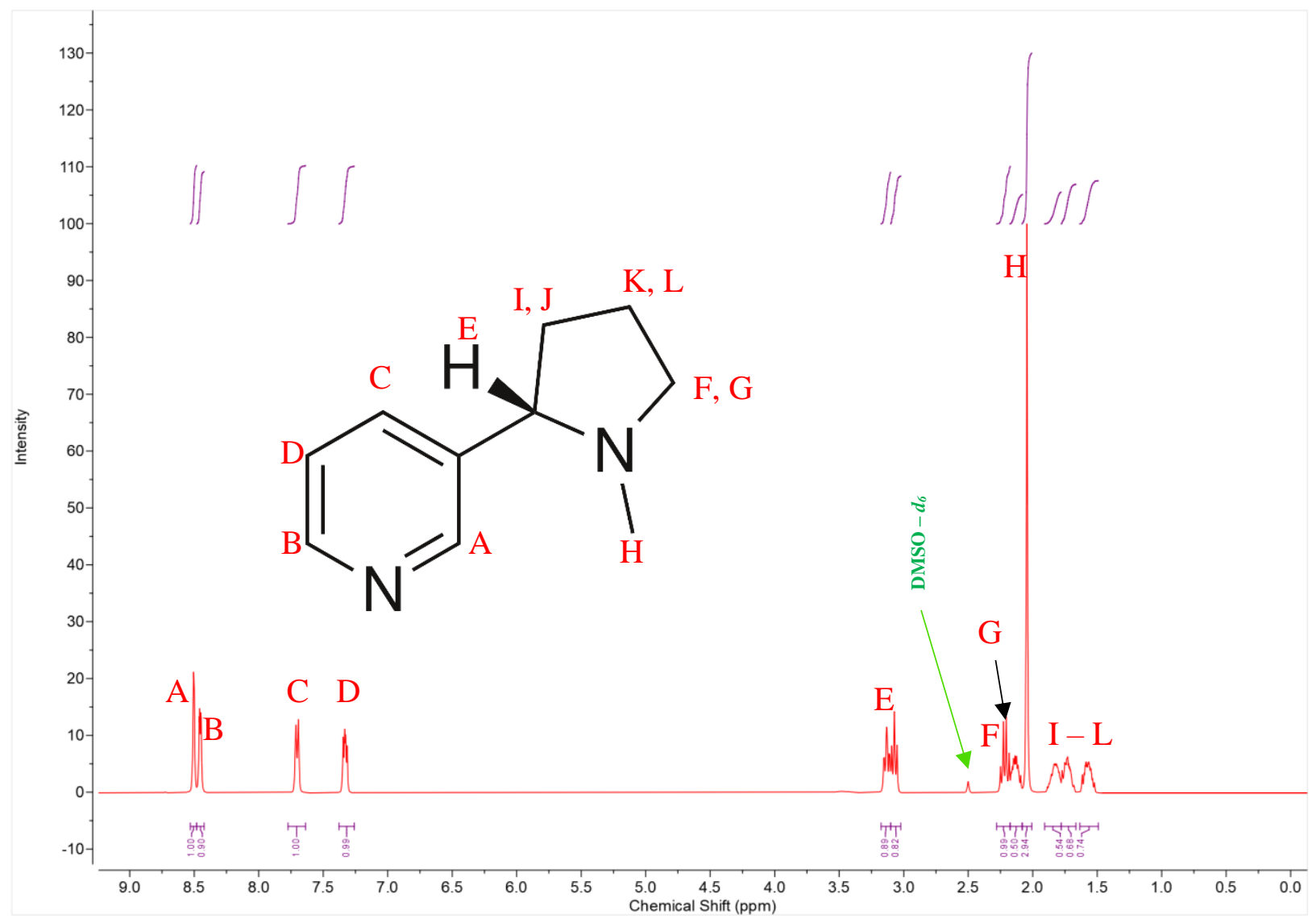

Figure S27: ${ }^{1} \mathrm{H}-\mathrm{NMR}$ spectrum for (S)-nicotine from the bottle. 


\section{UV Degradation Studies ${ }^{1}$ H-NMR Spectra}

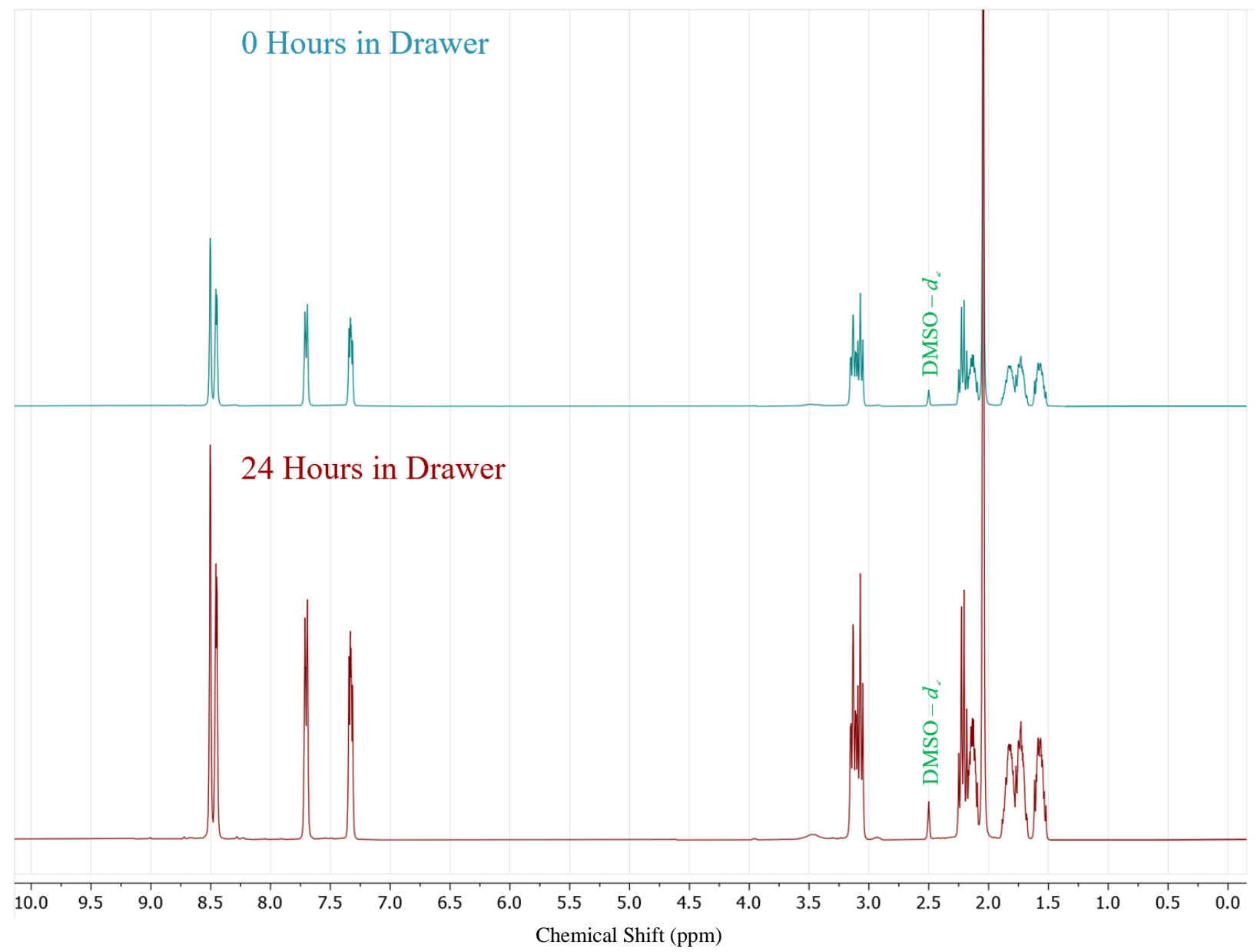

Figure S28: ${ }^{1} \mathrm{H}-\mathrm{NMR}$ spectra of solutions of (S)-nicotine prepared from samples in which the liquid was in a vial in a dark drawer for either 0 hours (upper) or 24 hours (lower). 


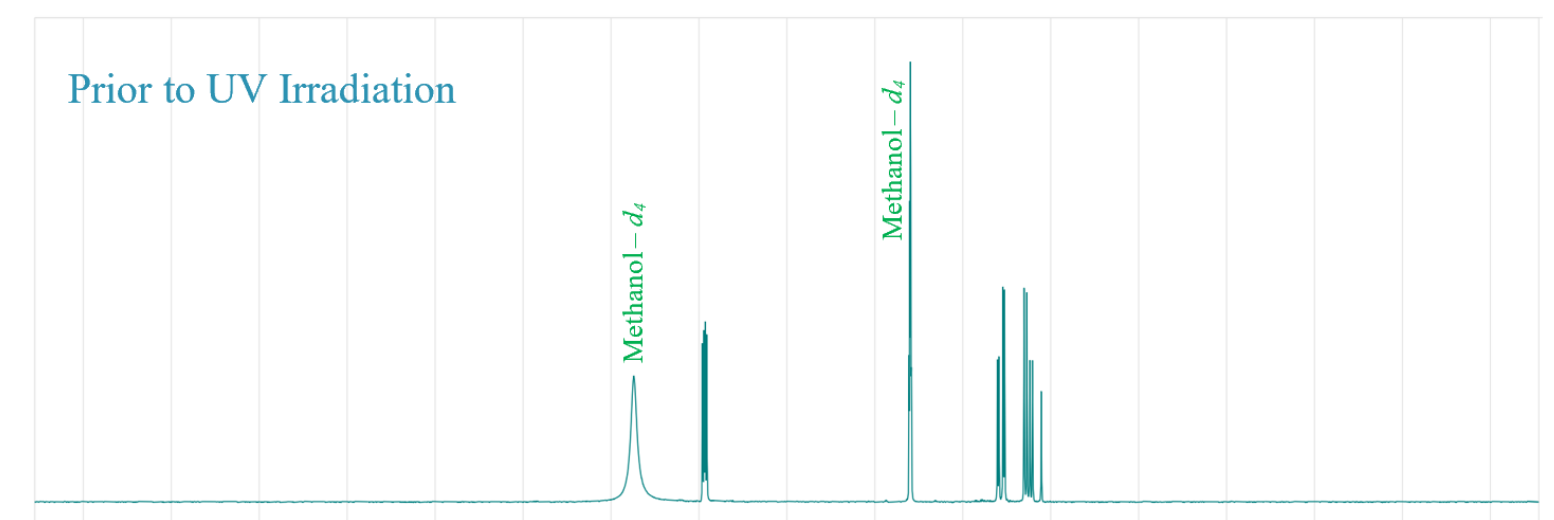

After 24 Hours UV Irradiation

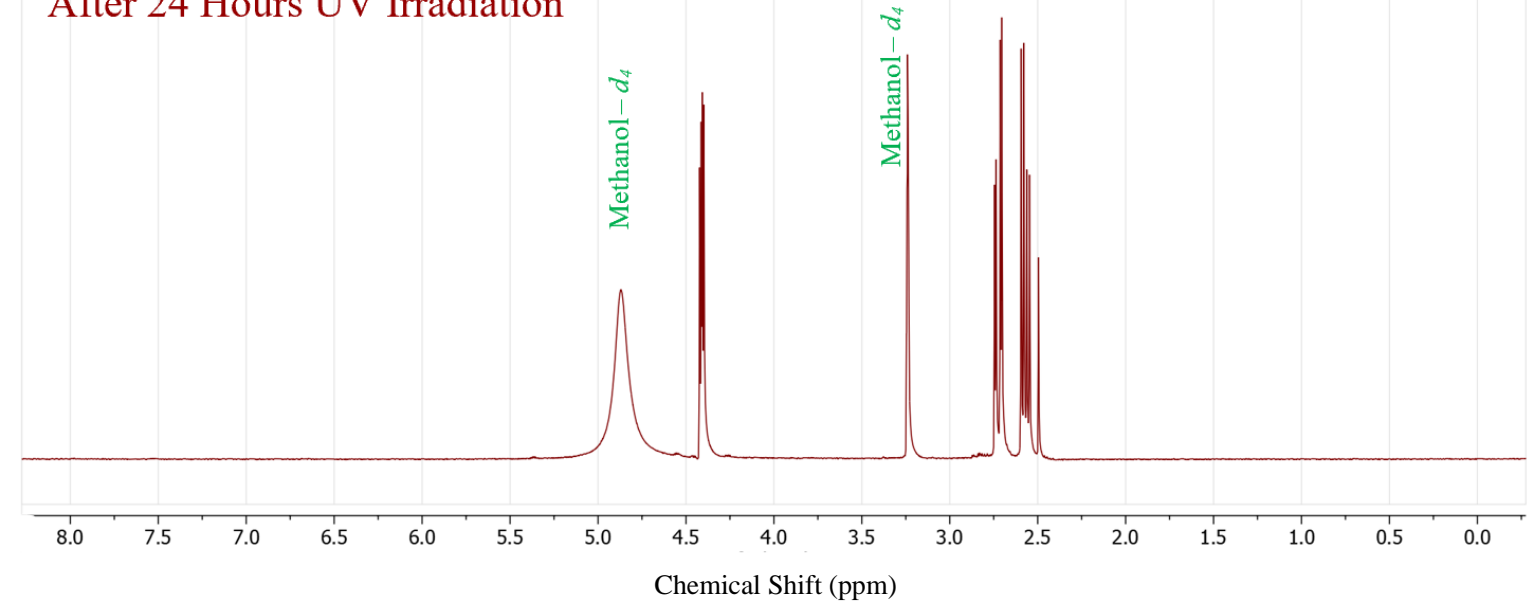

Figure S29: ${ }^{1} \mathrm{H}-\mathrm{NMR}$ spectra of solutions of L-malic acid prepared from samples in which the crystalline phase received either no UV irradiation (upper) or 24 hours of UV irradiation (lower). 


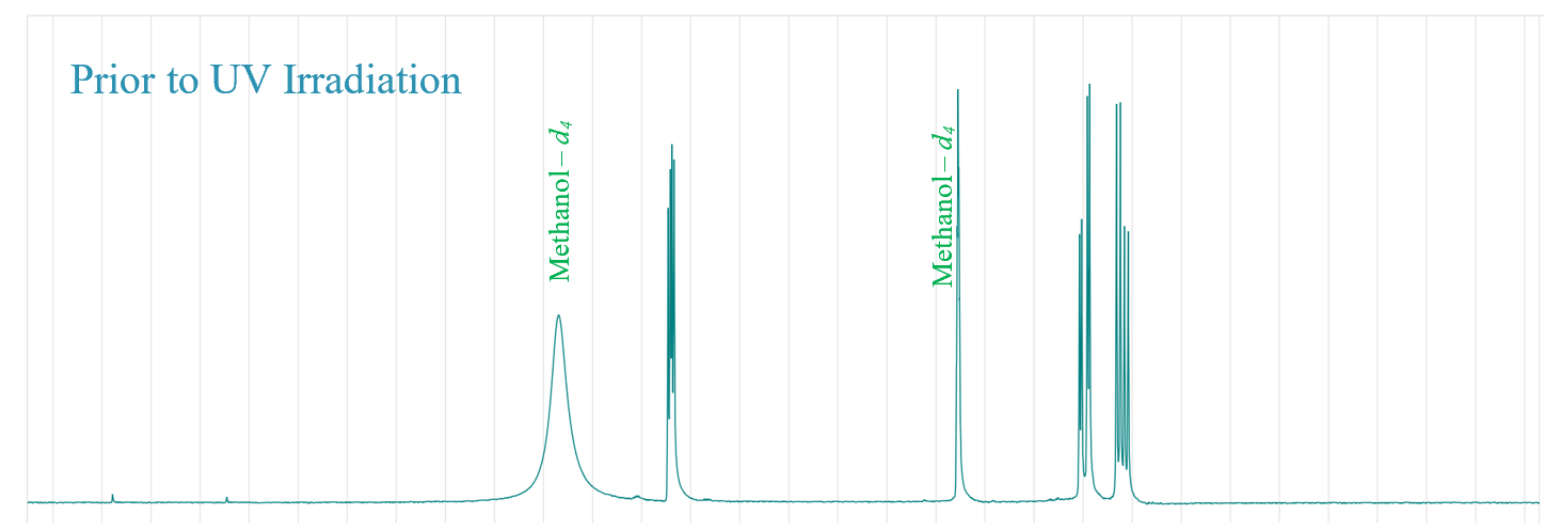

After 24 Hours UV Irradiation

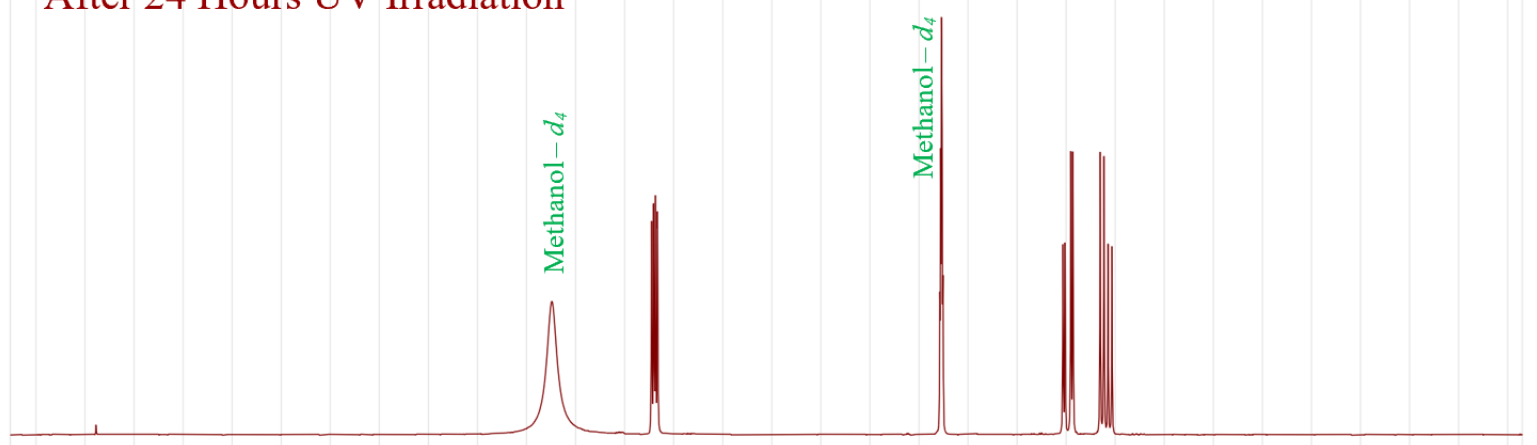

$\begin{array}{llllllllllllllllllllllllllllllllll}7.0 & 6.8 & 6.6 & 6.4 & 6.2 & 6.0 & 5.8 & 5.6 & 5.4 & 5.2 & 5.0 & 4.8 & 4.6 & 4.4 & 4.2 & 4.0 & 3.8 & 3.6 & 3.4 & 3.2 & 3.0 & 2.8 & 2.6 & 2.4 & 2.2 & 2.0 & 1.8 & 1.6 & 1.4 & 1.2 & 1.0\end{array}$ Chemical Shift (ppm)

Figure S30: ${ }^{1} \mathrm{H}-\mathrm{NMR}$ spectra of solutions of D-malic acid prepared from samples in which the crystalline phase received either no UV irradiation (upper) or 24 hours of UV irradiation (lower). 


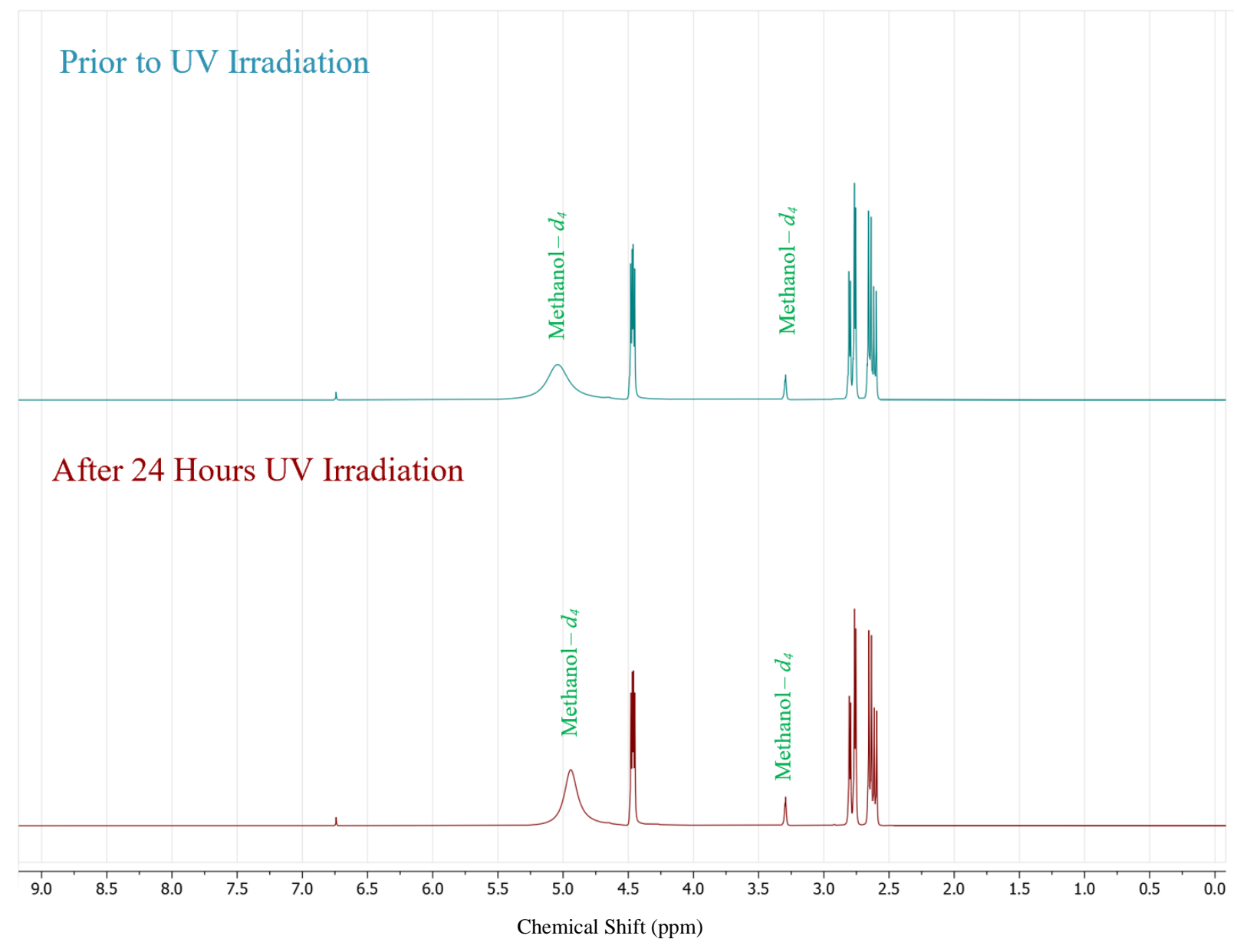

Figure S31: ${ }^{1} \mathrm{H}-\mathrm{NMR}$ spectra of solutions of DL-malic acid prepared from samples in which the crystalline phase received either no UV irradiation (upper) or 24 hours of UV irradiation (lower). 


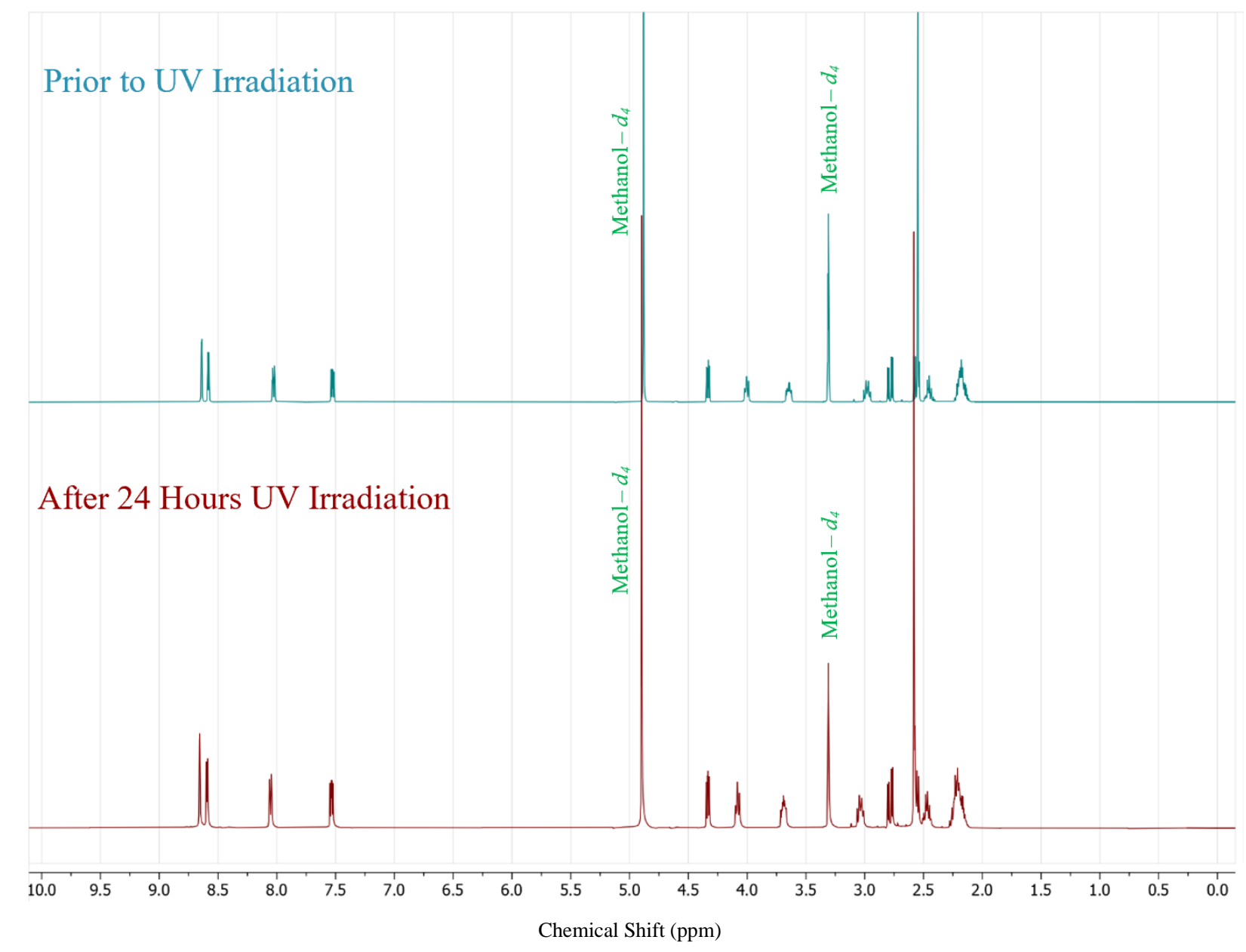

Figure S32: ${ }^{1} \mathrm{H}-\mathrm{NMR}$ spectra of solutions of Salt 1 prepared from samples in which the crystalline phase received either no UV irradiation (upper) or 24 hours of UV irradiation (lower). 


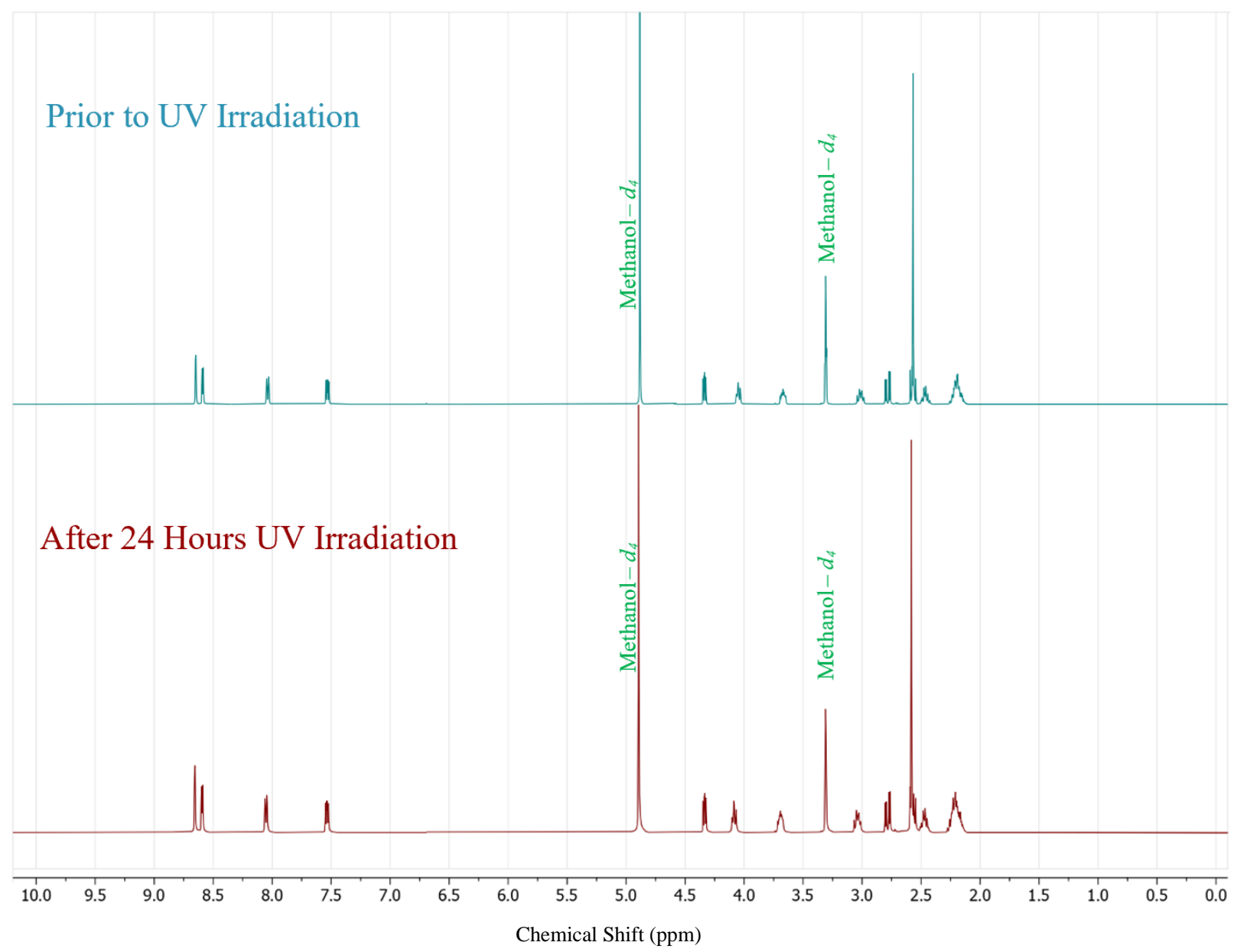

Figure S33: ${ }^{1} \mathrm{H}-\mathrm{NMR}$ spectra of solutions of Salt $\mathbf{3}$ prepared from samples in which the crystalline phase received either no UV irradiation (upper) or 24 hours of UV irradiation (lower). 


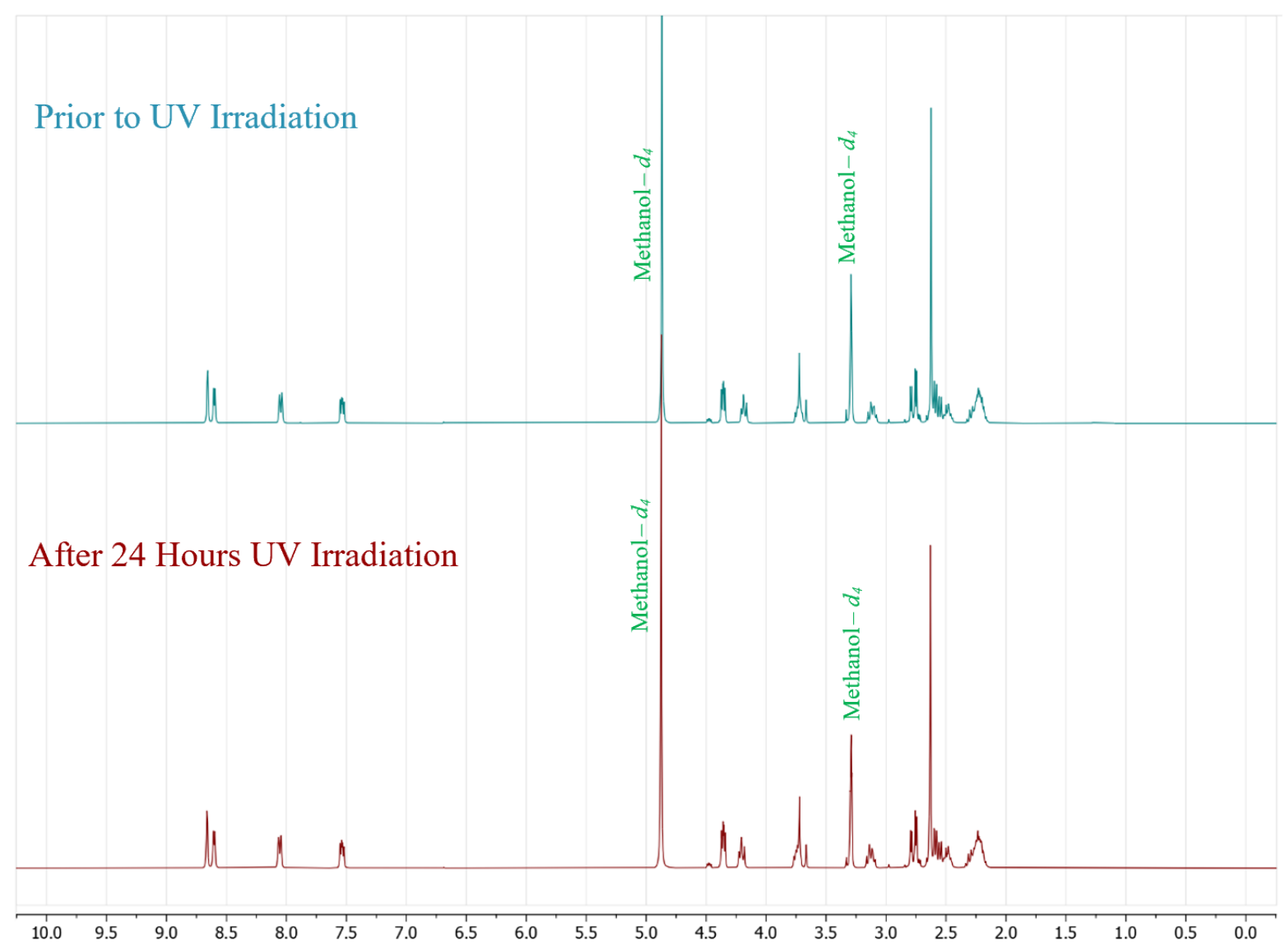

Figure S34: ${ }^{1} \mathrm{H}-\mathrm{NMR}$ spectra of solutions of Salt 4 prepared from samples in which the crystalline phase received either no UV irradiation (upper) or 24 hours of UV irradiation (lower). 